\title{
Hematopoietic stem cells fail to regenerate following inflammatory challenge.
}

Ruzhica Bogeska ${ }^{1,2}$, Paul Kaschutnig ${ }^{1,2,3}$, Malak Fawaz ${ }^{4}$, Ana-Matea Mikecin $^{1,2}$, Marleen Büchler-Schäff ${ }^{1,2,3}$, Stella Paffenholz ${ }^{1,2,3}$, Noboru Asada ${ }^{5}$, Felix Frauhammer ${ }^{3,6}$, Florian Buettner ${ }^{7}$, Melanie Ball ${ }^{1,2}$, Julia Knoch ${ }^{1,2}$, Sina Stäble ${ }^{1,2,3,8}$, Dagmar Walter ${ }^{1,2}$, Amelie Petri, ${ }^{1,2}$, Martha J. CarreñoGonzalez ${ }^{1,2,3}$, Vinona Wagner ${ }^{1,2,3}$, Benedikt Brors ${ }^{6}$, Simon Haas ${ }^{2,9,10}$, Daniel B. Lipka $^{8,11,12,13}$, Marieke A.G. Essers ${ }^{2,10,14}$, Tim Holland-Letz ${ }^{15}$, Jan-Philipp Mallm $^{16}$, Karsten Rippe ${ }^{16}$, Paul S. Frenette ${ }^{5}$, Michael A. Rieger ${ }^{4,12,17,18}$, Michael D. Milsom ${ }^{1,2,10,{ }^{*}}$.

${ }^{1}$ Division of Experimental Hematology, German Cancer Research Center (DKFZ), Heidelberg, Germany.

${ }^{2}$ Heidelberg Institute for Stem Cell Technology and Experimental Medicine (HI-STEM).

${ }^{3}$ Faculty of Biosciences, University of Heidelberg, Heidelberg, Germany.

${ }^{4}$ Department of Medicine, Hematology/Oncology, Goethe University Hospital Frankfurt, Frankfurt, Germany.

${ }^{5}$ Ruth L. and David S. Gottesman Institute for Stem Cell and Regenerative Medicine Research, Albert Einstein College of Medicine, Bronx, New York, USA.

${ }^{6}$ Division of Applied Bioinformatics, DKFZ, Heidelberg, Germany.

${ }^{7}$ Helmholtz Zentrum Munich-German Research Center for Environmental Health, Institute of Computational Biology, Neuherberg, Germany.

${ }^{8}$ Section Translational Cancer Genomics, Division of Translational Medical Oncology, DKFZ, Heidelberg, Germany.

${ }^{9}$ Division of Stem Cells and Cancer, DKFZ Heidelberg, Germany.

${ }^{10}$ DKFZ-ZMBH Alliance, Heidelberg, Germany.

${ }^{11}$ National Center for Tumor Diseases (NCT) Heidelberg, Germany.

${ }^{12}$ The German Cancer Consortium (DKTK), Heidelberg, Germany.

${ }^{13}$ Faculty of Medicine, Otto-von-Guericke-University, Magdeburg, Germany.

${ }^{14}$ Division of Inflammatory Stress in Stem Cells, DKFZ, Heidelberg, Germany.

${ }^{15}$ Division of Biostatistics, DKFZ, Heidelberg, Germany.

${ }^{16}$ Division of Chromatin Networks, DKFZ, Heidelberg, Germany.

${ }^{17}$ Frankfurt Cancer Institute, Frankfurt, Germany.

${ }^{18}$ Cardio-Pulmonary Institute, Frankfurt, Germany

*Lead Author to whom correspondence should be addressed. michael.milsom@dkfz.de 
41 Abstract:

42 Hematopoietic stem cells (HSCs) are canonically defined by their

43 capacity to maintain the HSC pool via self-renewal divisions. However, 44 accumulating evidence suggests that HSC function is instead preserved 45 by sustaining long-term quiescence. Here, we study the kinetics of HSC 46 recovery in mice, following an inflammatory challenge that induces 47 HSCs to exit dormancy. Repeated inflammatory challenge resulted in a 48 progressive depletion of functional HSCs, with no sign of later recovery. 49 Underlying this observation, label retention experiments demonstrated 50 that self-renewal divisions were absent or extremely rare during 51 challenge, as well as during any subsequent recovery period. While 52 depletion of functional HSCs held no immediate consequences, young 53 mice exposed to inflammatory challenge developed blood and bone 54 marrow hypocellularity in old age, similar to elderly humans. The 55 progressive, irreversible attrition of HSC function demonstrates that 56 discreet instances of inflammatory stress can have an irreversible and 57 therefore cumulative impact on HSC function, even when separated by 58 several months. These findings have important implications for our 59 understanding of the role of inflammation as a mediator of dysfunctional 60 tissue maintenance and regeneration during ageing. 


\section{Main:}

Within regenerating tissues, adult stem cells are thought to comprise a life-long reserve from which mature cells are ultimately replenished in response to normal turnover or following depletion resulting from injury. The critical concept underlying this hypothesis is that adult stem cells are thought to possess extensive self-renewal potential in vivo, being capable of reversibly switching from quiescence to active proliferation in order to sustain hematopoiesis (Wilson et al., 2008). In such a setting, the functional status of stem cells would be preserved, regardless of the degree to which they had contributed to production of mature cells. However, such a scenario is not compatible with the popular notion that the progressive attrition of stem cell function is an important root cause of a number of diseases, particularly in the context of ageing (Lopez-Otin et al., 2013).

In the mammalian blood system, HSCs typically exist in a quiescent state and are thought to infrequently contribute towards mature blood cell production under homeostatic conditions (Busch et al., 2015; Cheshier et al., 1999; Sun et al., 2014). Label retention experiments in the laboratory mouse illustrate the heterogeneous proliferative behavior of native HSCs and demonstrate that so-called "dormant" HSCs, which possess a comparatively low division history, retain the highest functional potency compared to their more frequently dividing counterparts (Bernitz et al., 2016; Foudi et al., 2009; Qiu et al., 2014; Sacma et al., 2019; Wilson et al., 2008). Such a finding suggests that HSC potency gradually decreases with increasing rounds of cell division and that self-renewal divisions do not occur, or are rare events (Hinge et al., 2020). In line with this concept, it has previously been shown that 
repeated exposure to stress agonists that increase HSC division rate in vivo, such as inflammation and infection, can compromise HSC function (Esplin et al., 2011; Matatall et al., 2016; Pietras et al., 2014; Pietras et al., 2016; Rodriguez et al., 2009; Takizawa et al., 2017). In the setting of a murine genetic model of bone marrow (BM) failure, such challenge resulted in the exhaustion of HSC reserves and subsequent development of severe aplastic anemia, demonstrating the biological relevance of this finding (Walter et al., 2015). In this study, we sought to explore the broader implications of these findings in the context of normal hematopoiesis and specifically interrogate whether there was any evidence of regeneration of the HSC pool in this setting.

The acute challenge of mice with the toll-like receptor 3 agonist, polyinosinic:polycytidylic acid ( $\mathrm{pl}: \mathrm{pC})$, leads to induction of interferon- $\alpha$, transient peripheral blood (PB) cytopenias and a parallel increase in proliferation of long-term HSCs (LT-HSCs), all of which return to homeostatic levels within 4 days (Figure S1A) (Essers et al., 2009; Walter et al., 2015). To assess the effects of repeated inflammatory challenge, wild-type C57BL/6J mice were subjected to a pl:pC dose escalation regimen, with analysis of hematologic parameters performed after a four-week recovery period (Figure S1B). One to three rounds of pl:pC treatment, corresponding to 8 to 24 individual injections over the course of 8 to 24 weeks, failed to provoke any pronounced changes in PB and BM cellularity (Figures S1C-F). While the frequency and absolute number of phenotypic and transcriptionally-defined LT-HSCs in the BM of treated mice was comparable to phosphate buffered saline (PBS)-treated controls (CON), it was possible to discern a mild but 
111 significant decrease in the frequency of quiescent LT-HSCs after two or more

112 rounds of pl:pC treatment (Figures S1G-I, S2A-D). A more detailed

113 assessment of LT-HSC function in vitro, revealed that the clonogenic potential

114 of LT-HSCs isolated from mice treated with three rounds of $\mathrm{pl}: \mathrm{pC}\left(\mathrm{Tx}^{3 \mathrm{x}}\right)$ was

115 reduced compared to those from $\mathrm{CON}$ mice (Figures $1 \mathrm{~A}-\mathrm{B}$ ). There was a

116 marked decrease in the overall proliferative potential of individual LT-HSCs

117 from $\mathrm{Tx}^{3 \mathrm{x}}$ mice, which was most profoundly exhibited in clones producing

118 multi-potent progeny, as opposed to phenotypic LT-HSCs generating bi- or

119 uni-lineage progeny (Figures 1C, S2E). However, there was no evidence of

120 compromised proliferative potential within more mature HSC/progenitor

121 populations (Figure S2F). Continuous cell fate tracking experiments using

122 video microscopy demonstrated more rapid differentiation kinetics of $\mathrm{Tx}^{3 \mathrm{x}} \mathrm{LT}$ -

123 HSCs compared to CON LT-HSCs, as well as an accelerated exit from

124 quiescence into first cell cycle (Figures 1D-E). This may be indicative of cell

125 fate priming towards these outcomes as a result of past exposure to

126 inflammation. Taken together, these data suggest that while murine

127 hematopoiesis is restored following repeated $\mathrm{pl}: \mathrm{pC}$ challenge, the functional

128 capacity of LT-HSCs may be compromised.

129 In order to better address the functional capacity of LT-HSCs from mice

130 subject to repetitive induction of inflammation, competitive transplantation

131 assays were performed using BM harvested from mice exposed to one, two or

132 three rounds of $\mathrm{pl}: \mathrm{pC}$ treatment (Figure 1F). These data demonstrated a

133 progressive depletion of functional HSCs with increasing rounds of $\mathrm{pl}: \mathrm{pC}$

134 challenge, correlating with an approximate two-fold reduction in the level of

135 donor-derived hematopoiesis with each additional round of treatment (Figure 
136 1G-I). This cumulative depletion of functional HSCs following discrete rounds

137 of pl:pC challenge directly opposes the concept that the HSC pool is able to

138 regenerate in vivo following injury, via increased self-renewal-mediated HSC

139 expansion. In order to explore this phenomenon more comprehensively, $\mathrm{Tx}^{3 \mathrm{x}}$

140 mice were allowed to recover for 5,10 , or 20 weeks post-challenge, following

141 which, transplantation assays were performed to ascertain if there was any

142 evidence of regeneration of the functional HSC pool (Figures 2A, S3A-F).

143 Surprisingly, competitive transplantation revealed that there was no significant

144 regeneration of the reconstitution capacity of HSCs, even following an

145 extensive recovery period (Figures 2B-C). Limiting dilution transplantation

146 assays validated this important finding and demonstrated that there was

147 absolutely no recovery in the absolute number of functional HSCs following

148 pl:pC challenge, with $\mathrm{Tx}^{3 \mathrm{x}}$ mice still demonstrating an approximate 20 -fold

149 reduction in functional HSCs up to 20 weeks post-treatment compared to

150 CON mice (Figures 2D, S3G-H). To address whether these findings related to

151 compromised function of native HSCs, as opposed to defects that only

152 become manifest upon transplantation of HSCs from treated mice, reverse

153 transplantation experiments were performed (Figure 2E). Thus, an excess of

154 purified HSCs harvested from non-treated wild-type mice were transplanted

155 into $\mathrm{Tx}^{3 \mathrm{X}}$ recipient mice at 5, 10 or 20 weeks after treatment, in the absence of

156 any myeloablative conditioning. In stark contrast with CON recipients,

157 sustained multi-lineage engraftment of normal HSCs into $\mathrm{Tx}^{3 \mathrm{X}}$ recipients was

158 observed, even when the transplantation was performed up to 20 weeks post-

159 treatment (Figure 2F-G). This suggests that repeated inflammatory challenge

160 resulted in a durable suppression of recipient HSCs, facilitating engraftment of 
161 donor HSCs for an unprecedented length of time after treatment. This data

162 additionally demonstrates that the niche of $\mathrm{Tx}^{3 \mathrm{X}}$ mice is still capable of

163 functionally supporting multilineage hematopoiesis from the non-treated donor

164 HSCs, correlating with a lack of evidence for major permanent alterations in

165 the composition of niche cells or spatial distribution of HSCs relative to niche

166 landmarks following pl:pC treatment (Figures S4A-H).

To determine whether this progressive loss of HSC functionality was

168 linked to broad systemic inhibitory effects of inflammation, or was rather

169 associated with a cumulative increase in the in vivo division history of HSCs,

170 label-retention experiments were performed using the Scl-tTA;H2B-GFP

171 mouse model (Wilson et al., 2008), which facilitates inducible expression of

172 GFP fused to histone H2B in LT-HSCs. Thus, one week after inducing the

173 chase period, mice were injected with one treatment round of pl:pC or PBS

$174\left(\mathrm{Tx}^{1 \mathrm{X}}\right)$ (Figure 3A). Label-retaining LT-HSCs (LRCs), which demonstrated a

175 limited proliferative response to treatment, were then prospectively identified

176 and isolated from their non-label-retaining (nonLRCs) counterparts based on

177 levels of GFP fluorescence (Figure 3B). As expected, compared to PBS-

178 treated controls, $\mathrm{Tx}^{1 \mathrm{X}}$ mice had fewer BM LRCs and a reduced average level

179 of GFP fluorescence in the LT-HSC compartment, confirming that this

180 treatment regimen enforced LT-HSC division in vivo (Figures 3C-D). When

181 the functional potency of LT-HSCs was assessed in vitro, LRCs in Tx ${ }^{1 \mathrm{X}}$ group

182 maintained their proliferative potential despite exposure to systemic

183 inflammation (Figure $3 \mathrm{E}$ ). This demonstrates that $\mathrm{LRCs}$ in $\mathrm{Tx}^{1 \mathrm{X}}$ mice were

184 protected from the inhibitory effects of inflammation, and that an overall

185 decrease in potency of LT-HSCs results from a decreased frequency of LRCs 
186

187

within this compartment. This suggests that inflammation-associated loss of LT-HSC potency is directly linked to proliferation history and that self-renewal divisions do not appear to take place in vivo under these conditions.

To ascertain whether this irreversible depletion of BM HSC reserves eventually results in compromised hematopoiesis, eight week old mice were subjected to eight rounds of $\mathrm{pl}: \mathrm{pC}$ treatment $\left(T x^{8 \mathrm{x}}\right)$ and were then either analyzed at 18 months of age, or were analyzed once they reached 24 months of age (Figure S5A). As previously described for $\mathrm{Tx}^{3 \mathrm{x}}$ mice, functional HSCs were depleted in the BM of $\mathrm{Tx}^{8 \mathrm{X}}$ mice, as assessed by competitive transplantation, while the $\mathrm{PB}$ and $\mathrm{BM}$ parameters were not dramatically altered relative to $\mathrm{CON}$ mice, when analyzed 2 months after treatment (Figures S5B-F). However, at 24 months of age, $\mathrm{Tx}^{8 \mathrm{X}}$ mice developed mild PB cytopenias and BM hypocellularity associated with increased BM adipocytes (Figures 4A-F), consistent with the concept that the depletion of functional HSCs was causative for the subsequent decline in output of mature hematopoietic cells.

Taken together, our results demonstrate that inflammatory challenge results in a progressive irreversible depletion of functional LT-HSCs, linked to accumulating division history in the setting of little to no self-renewal. This data provides evidence that discrete episodes of exposure to inflammatory stress can have a cumulative effect on stem cell attrition over long periods of time. Such a model has clear implications for how functional HSCs can become depleted during aging.

These findings would appear to have parallels with the often cited but poorly defined phenomenon of stem cell exhaustion, where excessive self- 
211 renewal divisions, such as those induced by serial HSC transplantation, are

212 thought to eventually lead to the functional collapse of HSC clones (Orford

213 and Scadden, 2008). However, the label retention data that we present, rather

214 suggests that relatively modest stimulation of the quiescent HSC pool can

215 lead to functional attrition of the cells that respond to such stress stimuli, while

216 cells that remain dormant are preserved. In this setting, the residual HSC and

217 progenitor pool is clearly capable of sustaining hematopoiesis and responding

218 to any subsequent challenge. It is only after an extended passage of time

219 following depletion of the functional HSC pool that one observes

220 compromised production of mature blood cells. This partly mimics the mild PB

221 cytopenias, BM hypocellularity and accumulation of BM adipocytes, that

222 together comprise typical features of aged human hematopoiesis, but which

223 are not normally observed in experimental mice housed under laboratory

224 conditions (Biino et al., 2013; Guralnik et al., 2004; Hartsock et al., 1965;

225 Tuljapurkar et al., 2011).

226 The surprising revelation that LT-HSCs demonstrate little to no 227 capacity for self-renewal in response to inflammatory challenge may be more 228 broadly relevant to other adult stem cell populations and could explain the link 229 between so-called inflammaging and compromised tissue maintenance and 230 repair in the elderly.

\section{References}

233 Angerer, P., Haghverdi, L., Buttner, M., Theis, F.J., Marr, C., and Buettner, F. 234 (2016). destiny: diffusion maps for large-scale single-cell data in $R$. 235 Bioinformatics 32, 1241-1243.

236 Bernitz, J.M., Kim, H.S., MacArthur, B., Sieburg, H., and Moore, K. (2016). 237 Hematopoietic Stem Cells Count and Remember Self-Renewal Divisions. Cell 238 167, 1296-1309 e1210. 
239 Biino, G., Santimone, I., Minelli, C., Sorice, R., Frongia, B., Traglia, M., Ulivi,

240 S., Di Castelnuovo, A., Gogele, M., Nutile, T., et al. (2013). Age- and sex241 related variations in platelet count in Italy: a proposal of reference ranges 242 based on 40987 subjects' data. PLoS One 8, e54289.

243 Bockamp, E., Antunes, C., Maringer, M., Heck, R., Presser, K., Beilke, S., 244 Ohngemach, S., Alt, R., Cross, M., Sprengel, R., et al. (2006). Tetracycline245 controlled transgenic targeting from the SCL locus directs conditional expression to erythrocytes, megakaryocytes, granulocytes, and c-kitexpressing lineage-negative hematopoietic cells. Blood 108, 1533-1541.

Brennecke, P., Anders, S., Kim, J.K., Kolodziejczyk, A.A., Zhang, X., Proserpio, V., Baying, B., Benes, V., Teichmann, S.A., Marioni, J.C., et al. (2013). Accounting for technical noise in single-cell RNA-seq experiments. Nat Methods 10, 1093-1095.

Busch, K., Klapproth, K., Barile, M., Flossdorf, M., Holland-Letz, T., Schlenner, S.M., Reth, M., Hofer, T., and Rodewald, H.R. (2015). Fundamental properties of unperturbed haematopoiesis from stem cells in vivo. Nature 518, 542-546.

Cabezas-Wallscheid, N., Buettner, F., Sommerkamp, P., Klimmeck, D., Ladel, L., Thalheimer, F.B., Pastor-Flores, D., Roma, L.P., Renders, S., Zeisberger, P., et al. (2017). Vitamin A-Retinoic Acid Signaling Regulates Hematopoietic Stem Cell Dormancy. Cell 169, 807-823 e819.

Cheshier, S.H., Morrison, S.J., Liao, X., and Weissman, I.L. (1999). In vivo proliferation and cell cycle kinetics of long-term self-renewing hematopoietic stem cells. Proc Natl Acad Sci U S A 96, 3120-3125.

Esplin, B.L., Shimazu, T., Welner, R.S., Garrett, K.P., Nie, L., Zhang, Q., Humphrey, M.B., Yang, Q., Borghesi, L.A., and Kincade, P.W. (2011). Chronic exposure to a TLR ligand injures hematopoietic stem cells. J Immunol 186, 5367-5375.

Essers, M.A., Offner, S., Blanco-Bose, W.E., Waibler, Z., Kalinke, U., Duchosal, M.A., and Trumpp, A. (2009). IFNalpha activates dormant haematopoietic stem cells in vivo. Nature 458, 904-908.

Foudi, A., Hochedlinger, K., Van Buren, D., Schindler, J.W., Jaenisch, R., Carey, V., and Hock, H. (2009). Analysis of histone 2B-GFP retention reveals slowly cycling hematopoietic stem cells. Nat Biotechnol 27, 84-90.

Guralnik, J.M., Eisenstaedt, R.S., Ferrucci, L., Klein, H.G., and Woodman, R.C. (2004). Prevalence of anemia in persons 65 years and older in the United States: evidence for a high rate of unexplained anemia. Blood 104, 2263-2268.

Haas, S., Hansson, J., Klimmeck, D., Loeffler, D., Velten, L., Uckelmann, H., Wurzer, S., Prendergast, A.M., Schnell, A., Hexel, K., et al. (2015). Inflammation-Induced Emergency Megakaryopoiesis Driven by Hematopoietic Stem Cell-like Megakaryocyte Progenitors. Cell Stem Cell 17, 422-434.

Haetscher, N., Feuermann, Y., Wingert, S., Rehage, M., Thalheimer, F.B., Weiser, C., Bohnenberger, H., Jung, K., Schroeder, T., Serve, H., et al. (2015). STAT5-regulated microRNA-193b controls haematopoietic stem and progenitor cell expansion by modulating cytokine receptor signalling. Nat Commun 6, 8928.

Hartsock, R.J., Smith, E.B., and Petty, C.S. (1965). Normal Variations with Aging of the Amount of Hematopoietic Tissue in Bone Marrow from the 
Anterior Iliac Crest. A Study Made from 177 Cases of Sudden Death Examined by Necropsy. Am J Clin Pathol 43, 326-331.

Hinge, A., He, J., Bartram, J., Javier, J., Xu, J., Fjellman, E., Sesaki, H., Li, T., Yu, J., Wunderlich, M., et al. (2020). Asymmetrically Segregated Mitochondria Provide Cellular Memory of Hematopoietic Stem Cell Replicative History and Drive HSC Attrition. Cell Stem Cell 26, 420-430 e426.

$\mathrm{Hu}$, Y., and Smyth, G.K. (2009). ELDA: extreme limiting dilution analysis for comparing depleted and enriched populations in stem cell and other assays. J Immunol Methods 347, 70-78.

Kunisaki, Y., Bruns, I., Scheiermann, C., Ahmed, J., Pinho, S., Zhang, D., Mizoguchi, T., Wei, Q., Lucas, D., Ito, K., et al. (2013). Arteriolar niches maintain haematopoietic stem cell quiescence. Nature 502, 637-643.

Lopez-Otin, C., Blasco, M.A., Partridge, L., Serrano, M., and Kroemer, G. (2013). The hallmarks of aging. Cell 153, 1194-1217.

Love, M.I., Huber, W., and Anders, S. (2014). Moderated estimation of fold change and dispersion for RNA-seq data with DESeq2. Genome Biol 15, 550. Matatall, K.A., Jeong, M., Chen, S., Sun, D., Chen, F., Mo, Q., Kimmel, M., and King, K.Y. (2016). Chronic Infection Depletes Hematopoietic Stem Cells through Stress-Induced Terminal Differentiation. Cell Rep 17, 2584-2595.

Nestorowa, S., Hamey, F.K., Pijuan Sala, B., Diamanti, E., Shepherd, M., Laurenti, E., Wilson, N.K., Kent, D.G., and Gottgens, B. (2016). A single-cell resolution map of mouse hematopoietic stem and progenitor cell differentiation. Blood 128, e20-31.

Orford, K.W., and Scadden, D.T. (2008). Deconstructing stem cell selfrenewal: genetic insights into cell-cycle regulation. Nat Rev Genet 9, 115-128. Pietras, E.M., Lakshminarasimhan, R., Techner, J.M., Fong, S., Flach, J., Binnewies, M., and Passegue, E. (2014). Re-entry into quiescence protects hematopoietic stem cells from the killing effect of chronic exposure to type I interferons. J Exp Med 211, 245-262.

Pietras, E.M., Mirantes-Barbeito, C., Fong, S., Loeffler, D., Kovtonyuk, L.V., Zhang, S., Lakshminarasimhan, R., Chin, C.P., Techner, J.M., Will, B., et al. (2016). Chronic interleukin-1 exposure drives haematopoietic stem cells towards precocious myeloid differentiation at the expense of self-renewal. Nat Cell Biol 18, 607-618.

Qiu, J., Papatsenko, D., Niu, X., Schaniel, C., and Moore, K. (2014). Divisional history and hematopoietic stem cell function during homeostasis. Stem Cell Reports 2, 473-490.

Rieger, M.A., Hoppe, P.S., Smejkal, B.M., Eitelhuber, A.C., and Schroeder, T. (2009). Hematopoietic cytokines can instruct lineage choice. Science 325, 217-218.

Rodriguez, S., Chora, A., Goumnerov, B., Mumaw, C., Goebel, W.S., Fernandez, L., Baydoun, H., HogenEsch, H., Dombkowski, D.M., Karlewicz, C.A., et al. (2009). Dysfunctional expansion of hematopoietic stem cells and block of myeloid differentiation in lethal sepsis. Blood 114, 4064-4076.

Sacma, M., Pospiech, J., Bogeska, R., de Back, W., Mallm, J.P., Sakk, V., Soller, K., Marka, G., Vollmer, A., Karns, R., et al. (2019). Haematopoietic stem cells in perisinusoidal niches are protected from ageing. Nat Cell Biol 21, 1309-1320. 
Sun, J., Ramos, A., Chapman, B., Johnnidis, J.B., Le, L., Ho, Y.J., Klein, A., Hofmann, O., and Camargo, F.D. (2014). Clonal dynamics of native haematopoiesis. Nature 514, 322-327.

Takizawa, H., Fritsch, K., Kovtonyuk, L.V., Saito, Y., Yakkala, C., Jacobs, K., Ahuja, A.K., Lopes, M., Hausmann, A., Hardt, W.D., et al. (2017). PathogenInduced TLR4-TRIF Innate Immune Signaling in Hematopoietic Stem Cells Promotes Proliferation but Reduces Competitive Fitness. Cell Stem Cell 21, 225-240 e225. K.L., Kessinger, M.A., Lane, J.T., BJ, O.K., and Sharp, J.G. (2011). Changes in human bone marrow fat content associated with changes in hematopoietic stem cell numbers and cytokine levels with aging. J Anat 219, 574-581. Tumbar, T., Guasch, G., Greco, V., Blanpain, C., Lowry, W.E., Rendl, M., and Fuchs, E. (2004). Defining the epithelial stem cell niche in skin. Science 303, 359-363. M.C., Moehrle, B., Brocks, D., Bayindir, I., Kaschutnig, P., et al. (2015). Exit from dormancy provokes DNA-damage-induced attrition in haematopoietic stem cells. Nature 520, 549-552. Jaworski, M., Offner, S., Dunant, C.F., Eshkind, L., Bockamp, E., et al. (2008). Hematopoietic stem cells reversibly switch from dormancy to self-renewal during homeostasis and repair. Cell 135, 1118-1129. 

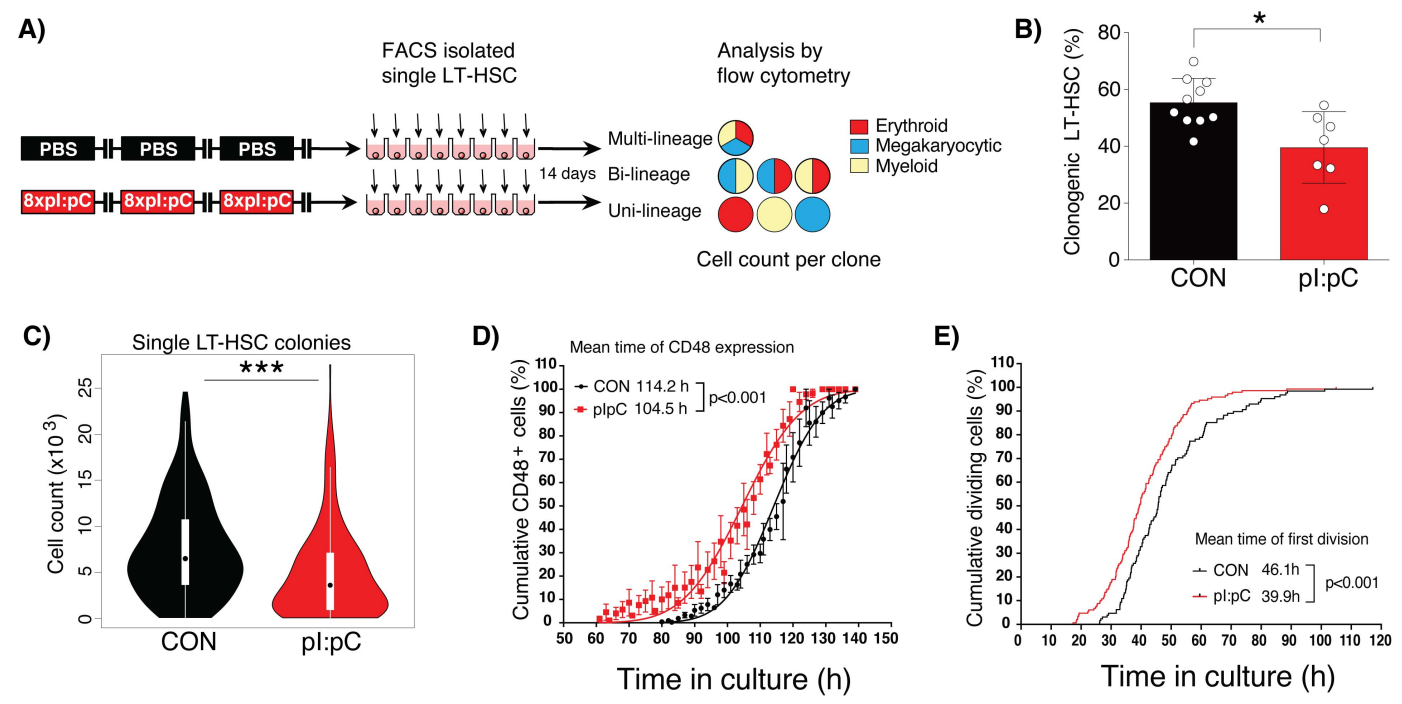

F)

G)

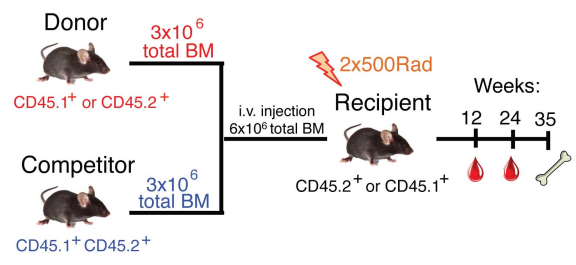

H)
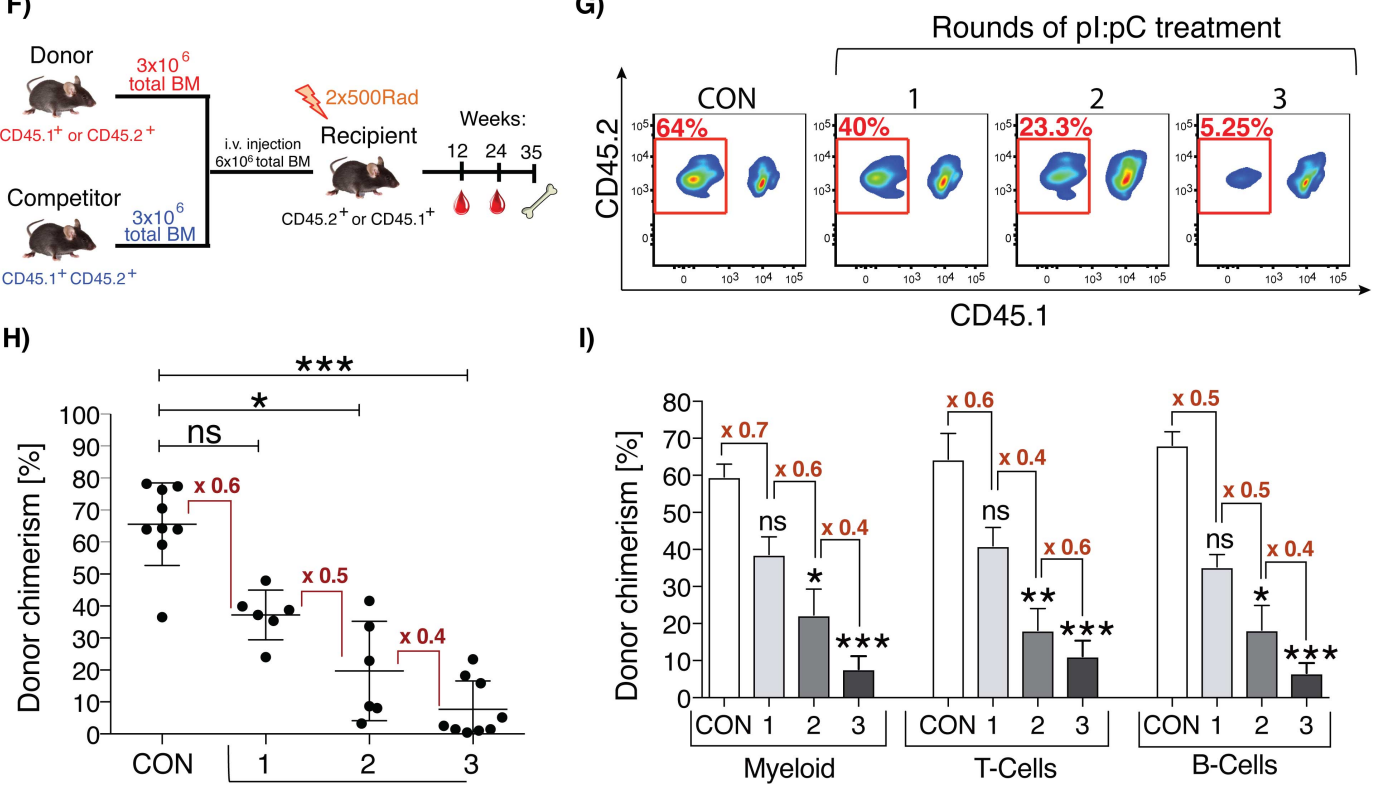

Rounds of pl:pC treatment

Rounds of pl:pC treatment

360 Figure 1. Repetitive exposure to inflammatory stress progressively

361 compromises the functional potency of LT-HSCs.

362 (A) Schematic representation of in vitro single cell liquid culture assay using 363 purified LT-HSCs. (B) The percentage of LT-HSC clones capable of forming 364 colonies is shown for LT-HSC isolated from CON or $\mathrm{TX}^{3 \mathrm{X}}$ mice (plus 365 mean $\pm S D, n=7-10$ mice). (C) Violin plots representing the total number of 366 daughter cells generated by each LT-HSC. (D\&E) In vitro time-lapse 
367 microscopy-based cell tracking, evaluating: (D) the cumulative percentage of 368 cells expressing CD48 versus time in culture, fitted to a Gaussian distribution 369 curve; (E) the cumulative incidence of LT-HSC having undergone first cell 370 division per unit time in culture (mean $\pm S D, n=128$ or 148 individual LT-HSCs

371 for CON or pl:pC groups, respectively; $\mathrm{n}=3$ independent biological repeats per

372 group). (F-I) Competitive repopulation assays were performed as described in 373 methods. PB was analyzed at 24 weeks post-transplantation. (F) Schematic 374 representation of the standard competitive transplantation assay (G) 375 Representative flow cytometry plots of total donor leukocyte chimerism in PB. 376 PB cells derived from donor BM isolated from pl:pC-treated or CON donors 377 are outlined in red. $\mathbf{( H )}$ Percentage total donor leukocyte chimerism in PB for 378 the indicated groups. Each dot represents transplantation outcome of BM 379 from an individual treated donor mouse (I) Percentage donor chimerism in 380 defined compartments of PB. Myeloid $=\mathrm{CD} 11 \mathrm{~b}^{+}, \quad$ T-cells $=\mathrm{CD}^{+} / \mathrm{CD}^{+}, \mathrm{B}-$ 381 cells $=B 220^{+}$(plus mean $\pm S D, n=8-9$ mice per group). $n s=P>0.05,{ }^{*} P<0.05$, 382 ${ }^{* *} \mathrm{P}<0.01,{ }^{* *} \mathrm{P}<0.001$ 
A)

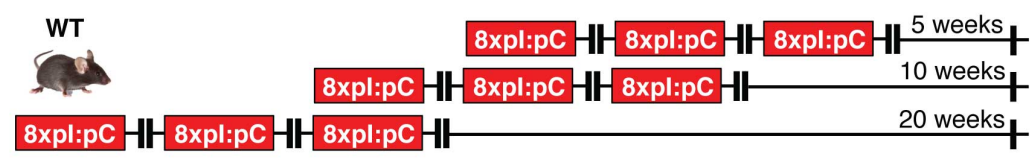

B)

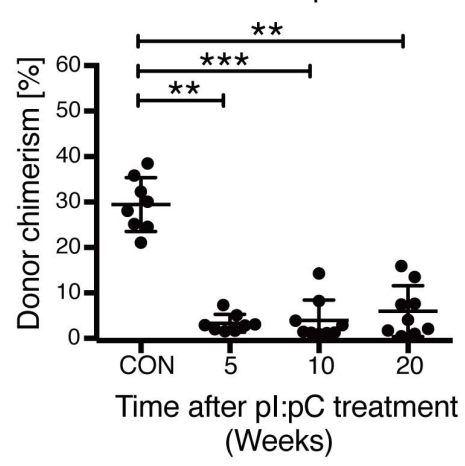

C)

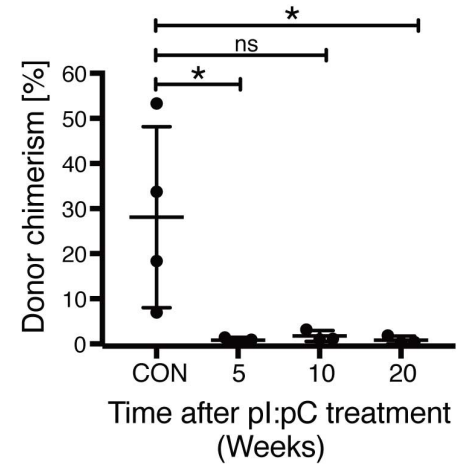

D)

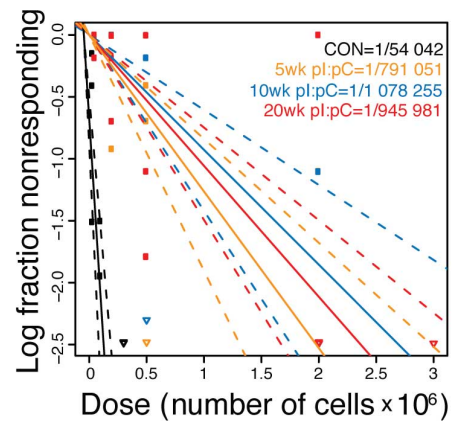

E)

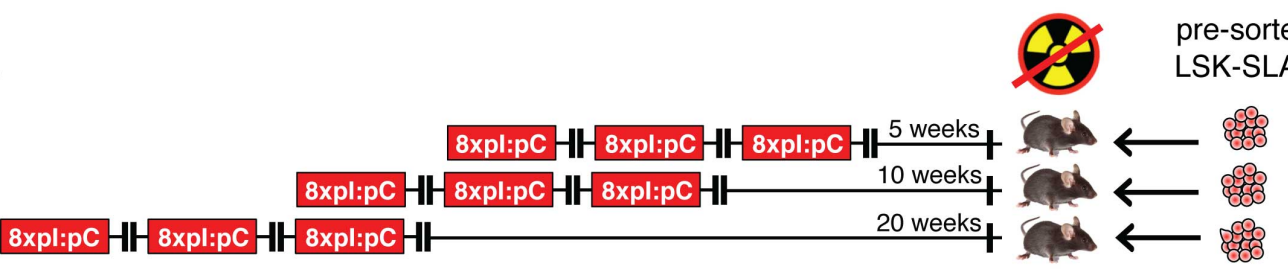

F)

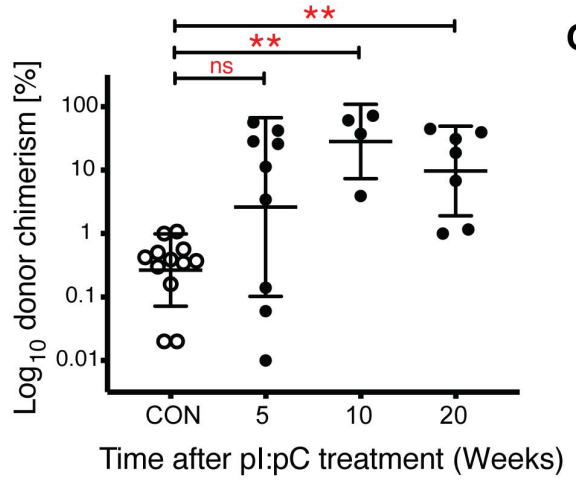

G)

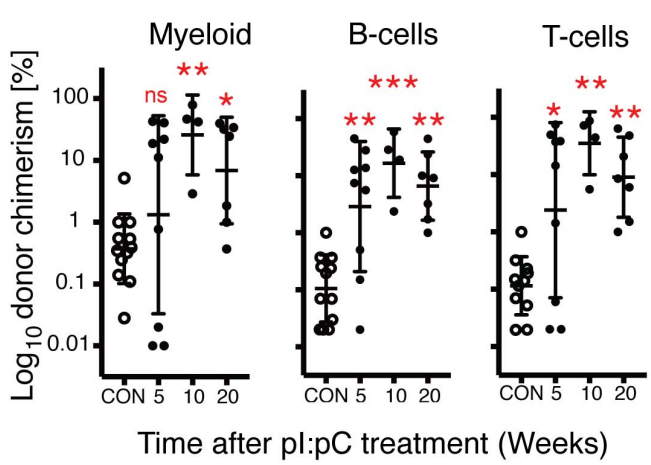

Figure 2. Lack of HSC functional recovery in vivo following inflammatory

stress.

(A) Schematic representation of treatment schedule incorporating increasing

387 duration of recovery post-challenge with pl:pC. (B\&C) Serial competitive repopulation assay using BM harvested from mice at indicated time points post-treatment: (B) Percentage total donor leukocyte chimerism at 24 weeks post-transplantation in primary recipients;

(C) Percentage total donor 
391 leukocyte chimerism at 24 weeks post-transplantation in secondary recipients.

392 Each dot represents transplantation outcome of BM from an individual treated

393 mouse or primary recipient mouse (plus mean \pm SD). (D) Limiting dilution

394 transplantation assays to determine LT-HSC frequency in BM isolated from

395 femora of individual mice. 95\% confidence intervals are indicated with dashed

396 lines $(n=6-9$ recipients per dilution, per donor, representing analysis of BM

397 from 3-4 individual treated donor mice). (E) Schematic representation of

398 reverse transplant experiment. Mice exposed to the indicated treatment

399 regimen were injected i.v. with saturating doses of purified donor HSCs in the

400 absence of any conditioning with irradiation. (F\&G) Percentage donor

401 contribution in PB at 24 weeks post-reverse transplantation to the following

402 defined populations: (F) total leukocytes; (G) Myeloid (CD11 b $\left.{ }^{+} / G R-1^{+}\right)$, B-cells

$403(\mathrm{~B} 220+)$ and T-cells $\left(\mathrm{CD}^{+} / \mathrm{CD}^{+}\right)$. Each dot indicates an individual treated

404 recipient (plus mean $\pm S D$ ). ns $=P>0.05,{ }^{*} P<0.05,{ }^{* *} P<0.01,{ }^{* * *} P<0.001$. 

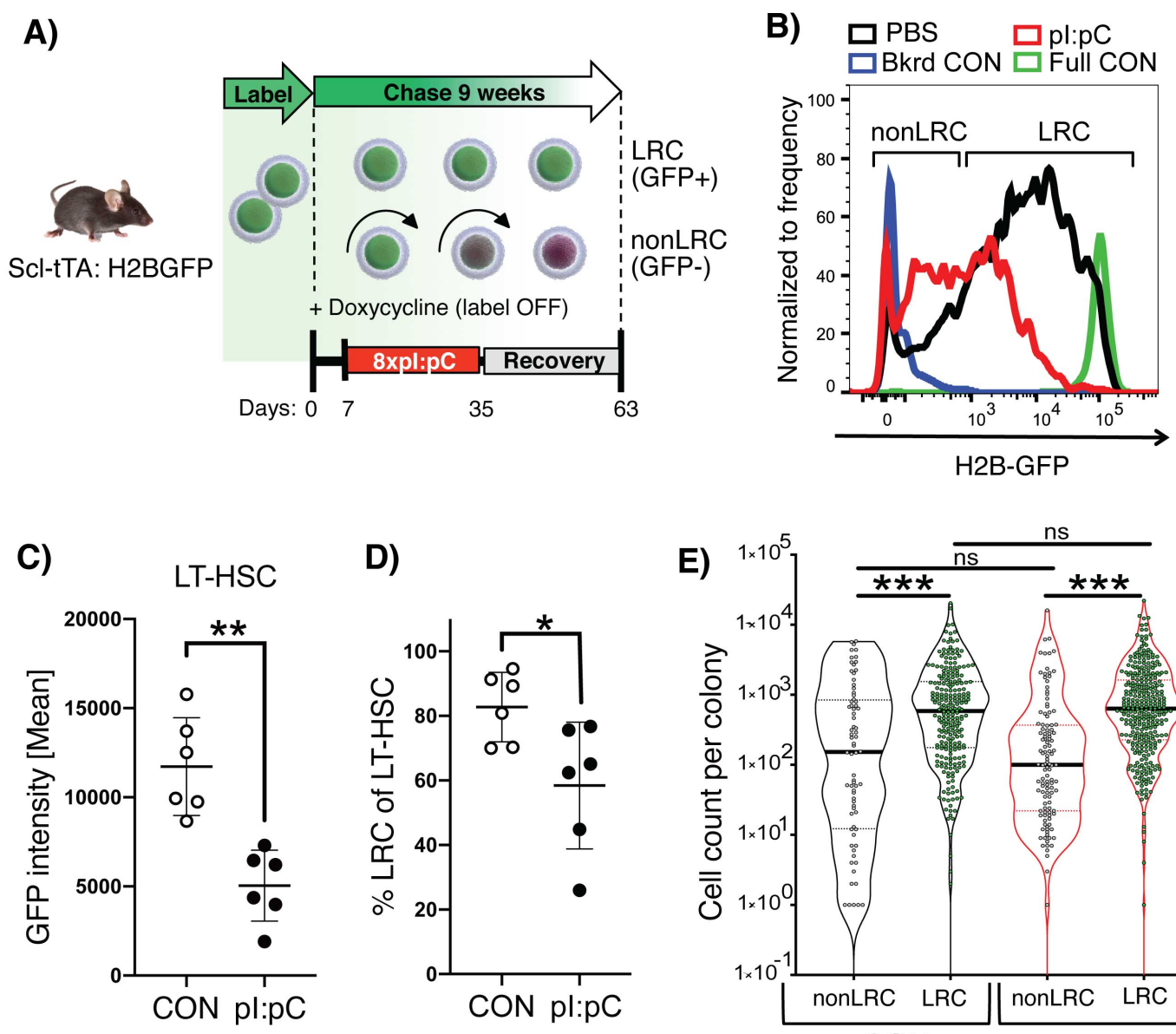

Figure 3. Inflammation-associated cell division leads to loss of LT-HSC potency.

408 (A) Schematic representation of combined label retention and treatment 409 schedule. Scl-tTA;H2B-GFP mice were treated with pl:pC or PBS (CON) as 410 indicated. Label chase was induced by sustained administration of 411 doxycycline starting 7 days before pl:pC/PBS treatment. Flow cytometry 412 analysis/sorting was performed on BM at 8 weeks after initiation of pl:pC/PBS 413 treatment. (B) Representative flow cytometry histograms of GFP fluorescence 414 in LT-HSCs from PBS and pl:pC treated mice. Background fluorescence 415 (Bkrd CON) and fully labeled (Full CON) controls are indicated (C) Mean 416 fluorescent intensity of GFP in LT-HSCs and (D) the proportion of LRCs within 417 the LT-HSC population in CON and pl:pC treated mice. Each dot represents a 
418 single mouse (plus mean \pm SD). (E) Violin plots showing the number of

419 progeny generated per individual LRC or nonLRC following 14 days in-vitro

420 culture ( $n=4-5$ mice per group, $n=280,364,293$ or 260 analyzed clones for

421 nonLRC CON, LRC CON, nonLRC pl:pC and LRC pl:pC, respectively. Solid

422 lines represent median, dashed lines interquartile range, $n s=P>0.05,{ }^{*} P<0.05$,

$\left.423 \quad{ }^{* *} \mathrm{P}<0.01,{ }^{* *} \mathrm{P}<0.001\right)$.

424 


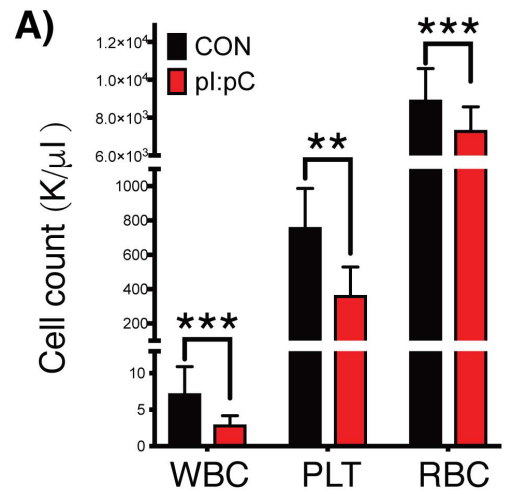

D)

CON
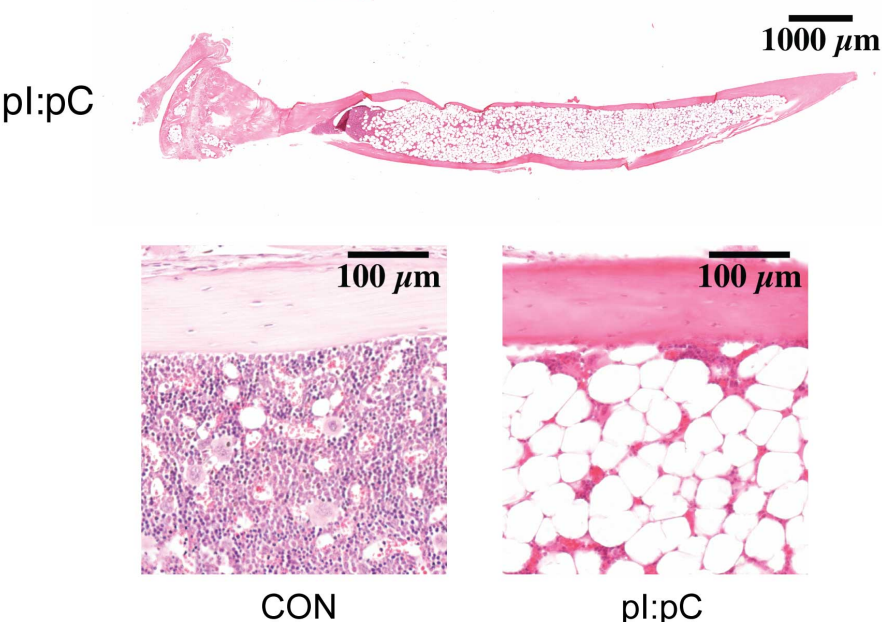

425 relevant features of ageing.
B)

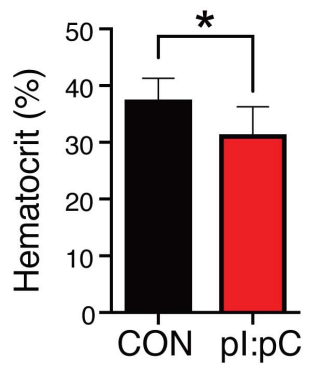

$\overline{1000 \mu \mathrm{m}}$

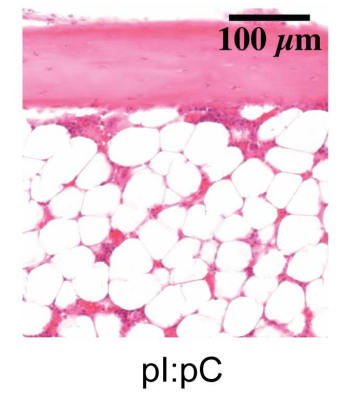

E)

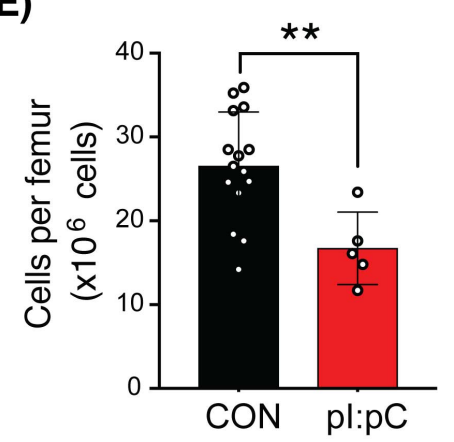

F)

C)
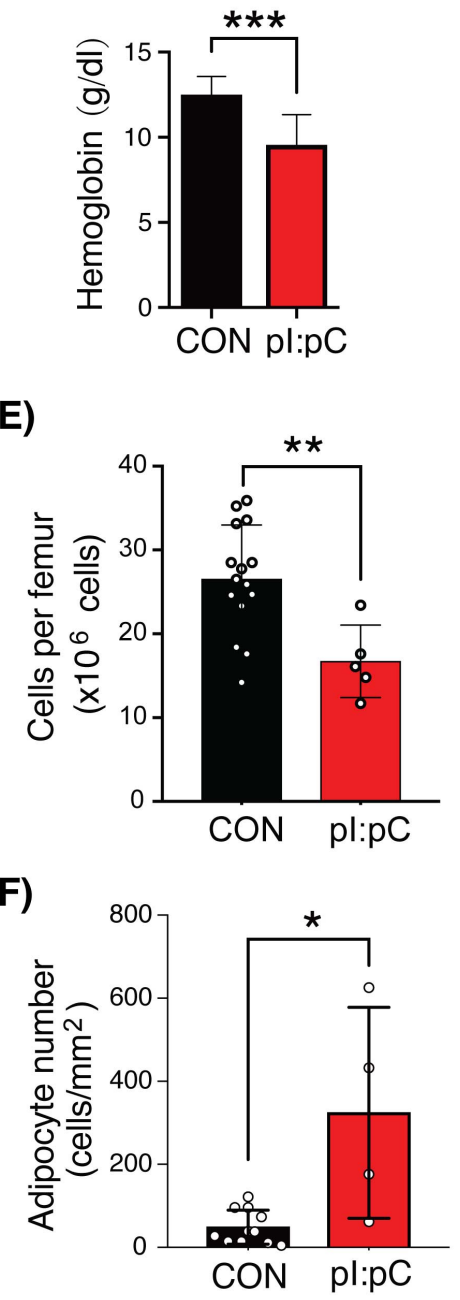

Figure 4. Repeated exposure to inflammatory stress provokes clinically

Mice were challenged repeatedly with $\mathrm{pl}: \mathrm{pC}$ or PBS in early/mid-life as illustrated in Figure S5A. At 24 months of age, the following hematologic parameters were assessed: (A) Leukocyte (WBC), platelet (PLT) and red blood cell (RBC) counts in PB; (B) PB hematocrit; (C) Hemoglobin; (D) Representative whole mount H\&E sections of tibiae; (E) BM cellularity per femur; and (F) Microscopy-based enumeration of adipocyte density within medullary cavity of tibiae ( $n=5-15$ mice per group). Circles represent individual treated aged mice (plus mean $\pm \mathrm{SD}$ ). ${ }^{*} \mathrm{P}<0.05,{ }^{* *} \mathrm{P}<0.01,{ }^{* * *} \mathrm{P}<0.001$ 
Methods

\section{Animals and animal experiments}

All animal experiments were approved by the local Animal Care and Use

439 Committees of the "Regierungspräsidium Karlsruhe für Tierschutz und

440 Arzneimittelüberwachung". Mice were maintained under specific pathogen-

441 free conditions in individually ventilated cages at the German Cancer

442 Research Center (DKFZ, Heidelberg) animal facility. Wild-type mice (C57BL/6

443 or B6.SJL-Ptprca Pepcb/BoyJ) were obtained from Harlan Laboratories,

444 Charles River Laboratories, or Janvier Laboratories. Unless otherwise

445 indicated, mice were 8 to 16 weeks old when experiments were initiated. H2B-

446 GFP and ScltTA mice have been previously described (Bockamp et al., 2006;

447 Tumbar et al., 2004; Wilson et al., 2008). H2B-GFP and ScltTA mice on a

448 C57BL/6 background were crossed in order to perform a label retaining cell

449 (LRC) assay. For the LRC assays, doxycyline treatment was performed by

450 supplementing the drinking water of experimental mice with $2 \mathrm{mg} / \mathrm{ml}$

451 doxycyline citrate (Sigma), sweetened with $20 \mathrm{mg} / \mathrm{ml}$ sucrose. Doxycycline-

452 supplemented drinking water was sustained for the duration of the label chase

453 period.

455 Treatment with pl:pC

456 To mimic a repetitive sterile inflammatory response in vivo, mice were 457 serially injected intraperitoneally (i.p.) with $5 \mathrm{mg} / \mathrm{kg}$ high molecular weight 458 polyinosinic:polycytidylic acid (pl:pC, InvivoGen), which had been 459 reconstituted in sterile physiologic saline precisely as described in the 
460 manufacturer's instructions. Control mice were injected with the same volume of PBS (Sigma Aldrich).

Bleeding and bone marrow isolation

Peripheral blood (PB) was collected by puncturing the craniofacial capillary bed of the mice and up to $100 \mu$ of PB was collected into EDTAcoated tubes. PB counts were evaluated using a Hemavet 950 FS veterinary blood cell counting machine (Drew Scientific).

For the purification of murine bone marrow (BM) cells, hind legs (femora, 469 tibia and iliac crests) and vertebrae were dissected by removing adherent soft 470 tissue and the spinal cord using a scalpel. Bones were either crushed or 471 flushed, and the resulting cell suspension was filtered through $40 \mu \mathrm{m}$ cell 472 strainers (Greiner Bio-One) and re-suspended in ice cold $2 \%$ (v/v) FCS/PBS 473 (PAA Laboratories/Sigma Aldrich) following centrifugation. When BM cells 474 were pooled from multiple mice, bones were gently crushed in Iscove's 475 modified Dulbecco's medium (IMDM, Life Technologies). Bones from 476 individual mice were harvested by flushing the cells out of two femurs into 2 $477 \mathrm{ml}$ ice cold $2 \%(\mathrm{v} / \mathrm{v})$ FCS/PBS or PBS using a $1 \mathrm{ml}$ syringe fitted with a 23 478 gauge needle.

480 Competitive repopulation transplantation assays

481 CD45.2 or CD45.1 C57BL/6 recipient mice were subject to total body 482 irradiation (2 x 5 Gy TBI, Bestrahlungsgerät/Buchler $\mathrm{GmbH}$, caesium source) 4832 to 16 hours prior to BM transplantation. Recipients were co-injected 484 intravenously (i.v.) with a mixture of $3 \times 10^{6}$ WT CD45.1/CD45.2 whole BM 
485

486

487

488

489

competitor cells and $3 \times 10^{6}$ WT CD45.1 or CD45.2 whole BM test donor cells (Figure 1F). BM from each individual test mouse (pl:pC or PBS) were separately transplanted into individual recipient mice. However, in order to facilitate high reproducibly, the co-injected competitor BM cells came from a common pool of cells, isolated from at least two donors. The same pool of competitor BM was used for all transplanted mice within each experimental repeat. To evaluate the repopulation potential of the test BM populations, PB and $\mathrm{BM}$ of recipient mice were analyzed by flow cytometry at three, six and eight months post-transplantation. PB and BM were stained with monoclonal antibodies against CD45.1 and CD45.2, in order to discriminate between reconstitution from test donor cells; competitor donor cells; and endogenous recipient cells. PB and BM were additionally stained with antibodies directed against B220, CD4, CD8a, CD11b; CD5, Gr-1, Ter-119, c-Kit, Sca-1, CD150 and CD48, in order to evaluate donor reconstitution within defined mature and immature cell populations. An aliquot of the input cell mix was separately stained and evaluated by flow cytometry to validate the correct ratio of cells was injected into recipient mice.

\section{Limiting dilution transplantation assays}

Total BM cells from pl:pC or PBS treated CD45.1 C57BL/6 mice were injected i.v. at different cell doses into cohorts of lethally irradiated CD45.2 recipient mice $\left(2 \times 5\right.$ Gy TBI), together with a fixed rescue dose of $2 \times 10^{5}$ CD45.1/CD45.2 BM cells. The BM of each test mouse was transplanted into 24 individual recipient mice. Recipients of BM from pl:pC-treated mice were injected with either $3 \times 10^{6}$ (6 recipients), $2 \times 10^{6}$ (60 recipients), $5 \times 10^{5}$ (60 
510 recipients), $2 \times 10^{5}$ (60 recipients) or $5 \times 10^{4} \mathrm{BM}$ cells (60 recipients), while

511 recipients of PBS-treated $\mathrm{BM}$ received either $3 \times 10^{5}$ (18 recipients), $1 \times 10^{5}$

512 (25 recipients) or $3 \times 10^{4}$ BM cells (25 recipients). At least three different

513 donor mice from each experimental group were individually assessed using

514 this methodology. Engraftment was assessed by flow cytometry analysis of

515 PB at six months post-transplantation. Mice that demonstrated $\geq 1 \%$ donor-

516 derived contribution to both myeloid $\left(\mathrm{Gr}-1^{+}\right.$and/or $\left.\mathrm{CD} 11 \mathrm{~b}^{+}\right)$and lymphoid

$517\left(\mathrm{~B}^{2} 20^{+}\right.$and/or $\mathrm{CD} 4^{+}$and/or $\left.\mathrm{CD}^{+}\right)$lineages in the PB were scored as positive

518 (responding) for engraftment. To estimate the frequency of repopulating HSCs

519 in the BM, a limiting dilution calculation was performed using the web-based

520 ELDA software provided at http://bioinf.wehi.edu.au/software/elda/ (Hu and

521 Smyth, 2009), using the number of responding mice at each cell dose as input

522 data.

524 Reverse transplantation experiments into non-conditioned mice

525 Recipient CD45.1 mice were treated with three rounds of pl:pC or PBS,

526 as illustrated in Fig. 2e. At 5, 10 or 20 weeks after treatment, mice were

527 injected i.v. with saturating doses of $\left(1.5-3 \times 10^{3}\right)$ FACS-purified Lineage',

$528 \mathrm{Sca}^{+}{ }^{+}, \mathrm{c}-\mathrm{Kit}^{+}, \mathrm{CD} 150^{+} \mathrm{BM}$ cells isolated from a CD45.2 donor. Importantly,

529 the recipients were not subject to any additional myelosuppressive

530 conditioning, such as total body irradiation or chemotherapy. The level of

531 donor chimerism in defined cell populations of the PB and BM was assessed

532 at six and eight months post-transplantation, respectively. 


\section{Fluorescent staining of PB and BM}

$537 \quad$ PB and BM were stained with monoclonal antibodies directed against 538 specific cell surface epitopes as detailed in Table S1. All antibodies had 539 previously been titrated and were used at a concentration where the mean

540 fluorescent intensity plateaus. Cells were incubated with the antibody mix in $5412 \% \mathrm{v} / \mathrm{v}$ FCS/PBS for $30 \mathrm{~min}$. at $4{ }^{\circ} \mathrm{C}$, washed with $2 \% \mathrm{FCS} / \mathrm{PBS}$ and then re542 suspended in $2 \%$ FCS/PBS containing 7-amino actinomycin (7-AAD, 543 Invitrogen) at a concentration of $5 \mu \mathrm{g} / \mathrm{ml}$. For PB samples, an additional 544 erythrocyte lysis step with $1 \mathrm{ml} \mathrm{ACK} \mathrm{lysing} \mathrm{buffer} \mathrm{(Lonza)} \mathrm{for} 10 \mathrm{~min}$. at room 545 temperature was carried out after the staining.

$547 \quad$ Flow cytometry analysis

548 After surface staining, cells were analyzed by flow cytometry using either 549 an LSRII or an LSRFortessa cytometer (Becton Dickinson) equipped with $550350 \mathrm{~nm}, 405 \mathrm{~nm}, 488 \mathrm{~nm}, 561 \mathrm{~nm}$ and $641 \mathrm{~nm}$ excitation lasers. Prior to the 551 analysis of cells, compensation was manually adjusted using OneComp 552 eBeads (eBioscience) stained with single antibodies. Analysis of flow 553 cytometric data was performed using FlowJo software (Tree Star). If not 554 indicated otherwise, populations were gated according to the markers listed in 555 Supplementary Information.

557 Cell cycle analysis

558 BM cells were stained with the LT-HSC antibody panel (Supplementary 559 Information). After surface staining, cells were lysed using ACK lysing buffer, 
560 washed with PBS and fixed with BD Cytofix/Cytoperm (BD Bioscience) for 20

561 min. at $4{ }^{\circ} \mathrm{C}$. Then, cells were washed twice with PermWash (BD Bioscience);

562 re-suspended in $100 \mu \mathrm{l}$ PermWash, containing mouse anti-human Ki-67

563 (Supplementary Information) and incubated overnight at $4{ }^{\circ} \mathrm{C}$. Shortly before

564 flow cytometry analysis, the cells were incubated with Hoechst33342 in a

$5651 / 400$ dilution for $10 \mathrm{~min}$. at $4{ }^{\circ} \mathrm{C}$.

566

567

568

569

570

571

572

573

574 584 lineage-positive cells were depleted using a magnetic particle concentrator 585 according to the manufacturer's instructions (Dynal MPC-6, Invitrogen). To

\section{Isolation of murine LSK/LT-HSC cells via FACS}

To purify low-density mononuclear cells (LDMNCs) from BM cells, three rounds of density gradient centrifugation using Histopaque 1083 (SigmaAldrich) were performed at room temperature. An equal volume of BM cell suspension $\left(2-10 \times 10^{7}\right.$ cells $\left./ \mathrm{ml}\right)$ was carefully layered on top of an equal volume of the Histopaque 1083 in a $15 \mathrm{ml}$ falcon tube (Greiner; Sarstedt). After centrifugation at room temperature at $300 \mathrm{~g}$ for $20 \mathrm{~min}$. with the brake switched off, the LDMNC fraction was collected without disturbing the pellet. The pellet was re-suspended and re-applied to Histopaque 1083 for the second round of density gradient centrifugation. In total, three rounds of centrifugation were performed. The fractions containing the LDMNCs were pooled and washed with ice-cold PBS. For lineage depletion, the LDMNC fraction was incubated with a panel of rat anti-mouse biotin-conjugated lineage markers $(4.2 \mu \mathrm{g} / \mathrm{ml}$ CD5, $4.2 \mu \mathrm{g} / \mathrm{ml}$ CD8a, $2.4 \mu \mathrm{g} / \mathrm{ml}$ CD11b, $2.8 \mu \mathrm{g} / \mathrm{ml}$ B220, $2.4 \mu \mathrm{g} / \mathrm{ml} \mathrm{Gr}-1,2.6 \mu \mathrm{g} / \mathrm{ml}$ Ter-119) for $45 \mathrm{~min}$. at $4{ }^{\circ} \mathrm{C}$. After washing with ice-cold PBS, the labeled LDMNCs were incubated with Biotin Binder Dynabeads at a ratio of 4 beads per input cell (Life Technologies) and the 
586 isolate the LSK/LT-HSC fraction by FACS, the resulting lineage-depleted cells

587 were subsequently stained with a panel of antibodies (c-Kit, Sca-1, CD150,

588 CD48, CD34), as indicated in Supplementary Information.

589 In order to maximize the yield of LRC and nonLRC LT-HSCs from

590 ScltTA;H2BGFP mice, density gradient centrifugation was omitted and lineage

591 depletion was performed directly after BM isolation. LRC and nonLRC LT-

592 HSC from ScltTA;H2B-GFP on doxycycline treatment were defined as follows.

593 Maximum GFP intensity was determined by flow cytometry of BM isolated

594 from a control ScltTA;H2B-GFP mouse not exposed to doxycycline treatment

595 (Full CON). The non-specific background GFP signal (Bkrd CON) was defined

596 in LT-HSCs from H2B-GFP mice. LT-HSCs showing GFP intensity above the

597 Bkrd CON were defined as LRCs, where LT-HSC with an overlapping GFP

598 intensity to the Bkrd CON were defined as nonLRC, as shown in Figure 3B.

599 Sorting experiments were performed using a BD FacsAria I, II or III flow 600 cytometer (BD Bioscience) at the DKFZ Flow Cytometry Service Unit, using a $601100 \mu \mathrm{m}$ nozzle and a maximum sort rate of 3 thousand cells per second. 602 Single cell sorts directly into 96 multi-well plates were performed using the 603 single cell precision mode, where the drop trajectory was adjusted for a 96604 well plate before each sort.

606 Microscopy analysis

607

608 Immunofluorescence imaging of BM niche components

609 Whole mount staining of HSCs in sternum bone marrow was performed 610 as previously described (Kunisaki et al., 2013). Briefly, Alexa Fluor 647-anti- 
611 CD144 (BV13) and Alexa Fluor 647-anti-CD31 (MEC13.3) (from Biolegend)

612 were injected i.v. 10 minutes before euthanizing mice, in order to stain BM

613 endothelial cells in vivo. Sternal bones were collected and transected with a

614 surgical blade into 2-3 fragments. The fragments were bisected sagitally for

615 the BM cavity to be exposed, and then fixed with $4 \%$ PFA for $30 \mathrm{~min}$. After

616 rinsing with PBS, bone pieces were blocked/permeabilized in PBS containing

$61720 \%(\mathrm{v} / \mathrm{v})$ normal goat serum and $0.5 \%(\mathrm{v} / \mathrm{v})$ TritonX-100. Primary antibodies

618 were incubated for approximately 36 hours at room temperature. After rinsing

619 the tissue with PBS, the tissues were incubated with secondary antibodies for

$6202 \mathrm{~h}$. The primary antibodies used were biotin-anti-Lineage (TER119, RB6-8C5,

621 RA3-6B2, M1/70, 145-2C11) (from BD Biosciences); biotin-anti-CD48 (HM48-

622 1), biotin-anti-CD41 (MWReg30) (from eBioscience); and Alexa Fluor 647-

623 anti-CD144 (BV13), PE-anti-CD150 (TC15-12F12.2) (from Biolegend). The

624 secondary antibody used was Streptavidin eFluor 450 (eBioscience). Images

625 were acquired using ZEISS AXIO examiner D1 microscope (ZEISS) with a

626 confocal scanner unit, CSUX1CU (Yokogawa), and reconstructed in three

627 dimensions with Slide Book software (Intelligent Imaging Innovations). Two-

628 sample Kolmogorov-Smirnov tests were used for comparisons of distribution

629 patterns. Statistical analyses were performed using GraphPad Prism 6

630 software.

631

632 Histology, hematoxylin and eosin (H\&E) staining

633 Tibiae were fixed in $10 \%$ formalin in PBS (v/v) for not longer than one

634 week and decalcified for five days in $0.5 \mathrm{M}$ EDTA (Ethylenediaminetetraacetic 635 acid) buffer ( $\mathrm{pH}$ 7.2). Bones were dehydrated in the Tissue-TeK-VIP Sakura 
636 tissue processor overnight and subsequently paraffin embedded using the

637 HistoStar embedding workstation (Thermo Scientific). Embedded bones were

638 cut with a Microtome (Microm HM 355S, Thermo Scientific) and stained with

639 Hematoxylin/Eosin (H\&E). In brief, bone sections were de-paraffinized and

640 rehydrated: 3 times in xylol for 5 minutes, 2 times in $100 \%$ ethanol, 2 times in

$64196 \%$ ethanol, 1 time in $70 \%$ ethanol and lastly transferred to VE water.

642 Slides were then stained in Mayer's haematoxylin for 5 minutes and then

643 rinsed under running tap water for 5 minutes. Subsequently, they were dipped

644 into acid $\mathrm{EtOH}(0,25 \%(\mathrm{v} / \mathrm{v}) \mathrm{HCl}$ in $70 \%(\mathrm{v} / \mathrm{v}) \mathrm{EtOH})$ and washed until the

645 sections were stained blue. They were counterstained with eosin for 1 minute,

646 dipped into $95 \% \mathrm{EtOH}$ and $100 \% \mathrm{EtOH}$ and put into xylene for 15 minutes.

647 The sections were then embedded in mounting media and dried overnight.

648 Imaging was performed with a Zeiss Axioplan widefield microscope.

650 Adipocyte quantification in H\&E sections

651 Adipocytes were counted from H\&E stained tibia sections. The images 652 were taken with an Axio Plan Zeiss Microscope equipped with Axio Cam ICc3

653 Zeiss (2.5x magnification) and processed with the ZEN program 2011.

654 Adipocyte quantification was performed in Fiji (ImageJ), where individual bone 655 marrow adipocytes, as defined by the following parameters: size (40-2000 656 pixel) and shape (circularity 0.4-1.00), were counted in a predefined surface 657 area. 
661 Single cell RNA-sequencing (scRNAseq)

662

LT-HSCs were purified by FACS, and single LT-HSC cells were

663 subsequently captured on a small sized IFC using the Fluidigm C1 system.

664 Briefly, cells were washed, re-suspended in PBS supplemented with C1

665 suspension buffer in a 4:1 ratio and 400 cells/ $\mu$ l were loaded onto the chip.

666 After cell capture, each position on the chip was imaged and only single cells

667 were included in the downstream library preparation and analysis. cDNA was

668 then amplified with the SMARTer Ultra Low RNA kit (Clontech) including

669 ERCC RNA spike-ins (ThermoFisher Scientific\# 4456740). Bulk controls were

670 also processed for each $\mathrm{C} 1$ run using 100 cells and the same reagent mixes

671 as used for the $\mathrm{C} 1$.

672

Amplified cDNA was checked with the TapeStation to assess both quality

673 and yield. Sequencing libraries were produced with the Illumina Nextera XT kit

674 according to the adopted Fluidigm protocol. All single cells from one C1 run

675 (about 70 cells on average) were pooled and sequenced 1x50 bp reads on an

676 Illumina HiSeq 2000 machine resulting in 2-3 million reads per cell.

677

scRNAseq bioinformatic analysis

679 For each cell, reads were aligned to the murine genome (ERCC 680 sequences concatenated to GRCm38.p4 version 84, softmasked) with STAR 681 version 2.5. For each cell, between 70 and $90 \%$ of the reads were uniquely 682 mapped. Raw counts were quantified from position-sorted alignment files with 683 HTSeq-count using mode 'union' and default quality thresholds of 10 . Cells 684 were excluded as low quality if more than $40 \%$ of counts were in ERCCs, or if 685 the counts in murine exons were more than $10 \%$ mitochondrial or less than 
6860.5 Mio in total. In addition, cells for which less than 2,000 genes were expressed were excluded; resulting in a total of 564 cells passing quality control. Size-factor normalization (Love et al., 2014) was used to identify

689 variable genes using a log-linear fit capturing the relationship between mean 690 and squared coefficient of variation (CV) of the log-transformed, TPM data 691 (Brennecke et al., 2013). Genes with a squared CV greater than the estimated 692 squared baseline CV were then considered as variable beyond technical 693 noise. This filter for highly variable genes resulted in 5176 genes. This set of 694 variable genes was used as input for downstream analysis, including 695 visualization and clustering.

A projection analysis was performed to integrate our own data with a larger hematopoietic dataset covering a wider range of blood stem and 698 progenitor cells (Nestorowa et al., 2016). To this end, the intersection of 699 variable genes identified in (Nestorowa et al., 2016) and our data was 700 established. A diffusion map representation of the 1656 cells from (Nestorowa 701 et al., 2016) was then generated, based on the 1616 genes that were variable 702 above technical noise both in our data and the data from (Nestorowa et al., 703 2016). Our cells were then projected into the diffusion map span based on the 704 diverse set of stem and progenitor cells from (Nestorowa et al., 2016) using 705 the destiny R package (Angerer et al., 2016).

\section{In vitro single cell growth assays}


LT-HSCs were directly flow sorted as individual cells per well into

711 retronectin pre-coated ultra-low attachment 96-well plates (Sigma-Aldrich) in

712 serum-free medium (StemSpan SFEM) containing $1 \%$ (v/v)

713 penicillin/streptomycin, $1 \%(\mathrm{v} / \mathrm{v})$ L-glutamine, and recombinant murine

714 cytokines that facilitate HSC growth and in-vitro differentiation into erythroid, myeloid and megakaryocytic lineages $(10 \mathrm{ng} / \mathrm{ml}$ Flt3-Ligand, $50 \mathrm{ng} / \mathrm{ml} \mathrm{SCF}$, $10 \mathrm{ng} / \mathrm{ml}$ TPO, $5 \mathrm{ng} / \mathrm{ml}$ IL-3, $10 \mathrm{ng} / \mathrm{ml} \mathrm{IL}-11,0.3 \mathrm{IU} / \mathrm{ml}$ Epo, $20 \mathrm{ng} / \mathrm{ml} \mathrm{IL}-7$, all

717 from PeproTech). During the clonogenic expansion, the single LT-HSCs were 718 cultured under hypoxic conditions $\left(5 \% \mathrm{O}_{2}\right), 37{ }^{\circ} \mathrm{C}, 5 \% \mathrm{CO}_{2}$ for $12-14$ days. 719 The differentiation potential (myeloid, erythroid, megakaryocytic) and 720 proliferative capacity (relative number of cells per colony) for each LT-HSC 721 colony was enumerated by flow cytometry, essentially as previously described 722 (Haas et al., 2015). Briefly, cells were directly stained with antibodies in the 723 well and the entire content of the well was run through the flow cytometer. The 724 percentage of cells contributing to the myeloid, erythroid or megakaryocytic 725 lineages within each LT-HSC colony was determined by the expression of 726 lineage specific markers (Gr-1/CD11b, Ter-119, CD71, CD4, CD42d).

728 Classification of the differentiation potential of single cell derived LT-HSC 729 clones

730 LT-HSCs were classified into 7 subgroups depending on whether they 731 had the potential to differentiate into a single cell type (unipotent cells: 732 myeloid, erythroid or megakaryocytic), into two cell types (bipotent cells: 733 myeloid-erythroid, myeloid-megakaryocytic, megakaryocytic-erythroid) or into 734 all three (multipotent cells). Cells were ascribed to these groups as follows. In 
735 order to account for different base frequencies of the three descendent cell

736 types all observed cell numbers were first normalized by the maximum

737 number of the respective cell type over all observed cells. Next, proportions of

738 the three normalized cell counts were calculated for each colony. In theory,

739 each unipotent LT-HSC should produce $100 \%$ of the specified descendent

740 cells, bipotent LT-HSC should ideally produce close to $50 \%$ each of the

741 normalized numbers of descendants and multipotent cells should produce

$74233.3 \%$ each. Thus, we plotted these theoretical subgroup means as well as

743 the actual cells in a graph illustrating the descendent proportions. As the

744 proportions add up to $100 \%$, a two-dimensional plot of any two of the

745 proportions is sufficient for this analysis. Each of the actual cells was then

746 classified into the subgroup it was closest to based on Euclidian distance. For

747 all data sets, each of the cells could thus be classified into one subgroup and

748 the proportion of the 7 subgroups could be determined. Differences in the

749 distribution of these proportions where then tested for statistical significance

750 using a Chi-Square test, using a significance level of alpha=5 \%. All

751 calculations were performed using $\mathrm{R}$, Version 3.2.0.

752

753 Statistical analysis

754

$755 \quad$ Unless otherwise indicated, data are presented as mean +/- standard

756 deviation. Statistical analyses were carried out in comparison to the control

757 group. For pairwise comparisons, two-sided unpaired non-parametric t-tests

758 were applied (Fig.1B, C; Fig.3 C, D; Fig.4 A, B, C, E, F). Comparisons of more

759 than two groups were performed by one-way analysis of variance (ANOVA) 
760 on ranks. If the ANOVA provided evidence that group means differed, Dunn's

761 multiple comparison tests were applied to determine which means amongst

762 the set of means differed from the rest (Fig.1H, I; Fig.2B, C, F, G; Fig.3E). To

763 evaluate the cumulative frequency distribution of CD48 expression on LT-

764 HSCs, the data was fitted to Gaussian distribution curves by least squares

765 regression. Best-fit values of the control and treatment datasets were

766 compared to each other by extra sum-of-squares $\mathrm{F}$ test (Fig.1D). Log-rank

767 Mantel-Cox test was used to test for statistically significant changes of first

768 LT-HSC division between the control and treatment group (Fig.1E). Variables

769 that showed skewed distribution were Log10 transformed (Fig.2F, G).

770 Statistical significance is indicated by one $(P<0.05)$, two $(P<0.01)$ or three

$771(P<0.001)$ asterisks. Analyses were performed using GraphPad Prism 5.0b

772 software (GraphPad Software, Inc., SanDiego, CA,

773 http.//www.graphpad.com).

775 Time-lapse imaging and single cell tracking

Time-lapse imaging and cell tracking were performed as previously

778 described (Cabezas-Wallscheid et al., 2017; Haetscher et al., 2015; Rieger et 779 al., 2009). LT-HSCs were FACS purified from pl:pC-treated or control mice 780 and seeded in 24-well plates equipped with silicon culture inserts (IBIDI, 781 Martinsried, Germany). Cells were pre-cultured in StemSpan SFEM medium 782 (StemCell Technologies) supplemented with $10 \mathrm{ng} / \mathrm{ml}$ Flt3-Ligand, $50 \mathrm{ng} / \mathrm{ml}$ $783 \mathrm{SCF}, 10 \mathrm{ng} / \mathrm{ml}$ TPO, $5 \mathrm{ng} / \mathrm{ml}$ IL-3, $10 \mathrm{ng} / \mathrm{ml}$ IL-11, 0.3 IU/ml Epo, 20 ng/ml IL-7 784 (PeproTech) recombinant murine cytokines and $0.1 \mathrm{ng} / \mathrm{ml}$ rat anti-mouse 
785 CD48-PE (clone HM48-1, eBioscience) for $17 \mathrm{~h}$ in a standard cell culture 786 incubator at $37{ }^{\circ} \mathrm{C}$ and $5 \% \mathrm{CO} 2$ for $\mathrm{CO} 2$ saturation, before being gastight 787 sealed with adhesive tape for live-cell microscopy. Time-lapse imaging was 788 performed using a CellObserver system (Zeiss, Hallbergmoos, Germany) at $78937^{\circ} \mathrm{C}$. Phase contrast images were acquired every 2-3 min over 7 days using 790 a 10x phase contrast objective (Zeiss), and an AxioCamHRm camera (at $7911388 \times 1040$ pixel resolution) with a self-written VBA module remote controlling 792 Zeiss AxioVision 4.8 software. PE fluorescence (Filter set F4-004, AHF 793 Analyzetechnik at $600 \mathrm{~ms}$ ) was detected every 2 hours. Cells were individually 794 tracked for their fates (apoptosis, division, loss of stemness) using a self795 written computer program (TTT) in concert with manual verification and analysis of results. The generation time of an individual cell was defined as

797 the time span from cytokinesis of its mother cell division to its own division. 798 Dead cells were identified by their shrunken, non-refracting and immobile 799 appearance. Induction of differentiation was detected by the appearance of 800 PE fluorescence (CD48 expression). The analysis did not rely on data 801 generated by an unsupervised computer algorithm for automated tracking.

\section{Acknowledgements:}

804 We thank members of the Division of Experimental Hematology for supporting 805 the experimental work described in this manuscript, and Steven Lane, 806 Thordur Oskarsson, Martin Sprick and Leonard Zon for critical proofreading of 807 this work. We also thank the Center for Preclinical Research DKFZ core 808 facility; the Flow Cytometry DKFZ core facility; the Single Cell Open Lab 809 DKFZ Core Facility; and Damir Krunic from the Light Microscopy DKFZ core 
810 facility. This work was supported by funding from the German Research

811 Foundation (DFG) SFB873 (MDM and MAGE), FOR2674 (MDM, DBL, BB,

$812 \mathrm{KR}$ and JPM) and SFB834 (MAR and MF); the Deutsche Jose Carreras

813 Leukämiestiftung (grant R15/09 to MDM and 10R/2017 to MAR); the Fritz

814 Thyssen Stiftung (grant 10.16.1.023MN to MDM); the Helmholtz

815 Zukunftsthema Aging and Metabolic Programming (AMPro) ZT-0026 (MDM

816 and DBL); the DKFZ-MOST German-Israel Cooperative Research Program

817 (MDM); the Cancer Transitional Research And Exchange Program (Cancer-

818 TRAX) within the German-Israeli Helmholtz International Research School

819 (SS); the National Institutes of Health RO1 DK056638 and R01 DK112976

820 (PF); the Wilhelm-Sander Foundation (grant 2018-116.1 to MAR); and the

821 Dietmar Hopp Stiftung (MDM and MAGE).

822

823 Author contributions:

$824 \mathrm{RB}, \mathrm{BB}, \mathrm{SH}, \mathrm{DBL}, \mathrm{MAGE}, \mathrm{KR}, \mathrm{PSF}, \mathrm{MAR}$ and MDM designed and directed

825 the experimental scheme of work; RB, PK, MF, AMM, MBS, SVP, NA, BM, $826 \mathrm{JK}, \mathrm{SS}, \mathrm{DW}, \mathrm{AP}, \mathrm{MJCG}, \mathrm{VW}$ and JPM performed experiments; RB, PK, MF, 827 FF, FB, BB, SH, DBL, MAGE, THL, JPM, KR, PSF, MAR and MDM carried 828 out data analysis and/or interpretation of experimental data; THL and RB 829 performed statistical analysis of the data; RB, MF, NA, FF, FB, PSF, MAR and 830 MDM wrote the manuscript.

831

832 Competing interests:

833 None of the authors have any relevant competing interests to declare. 
bioRxiv preprint doi: https://doi.org/10.1101/2020.08.01.230433; this version posted August 3, 2020. The copyright holder for this preprint (which was not certified by peer review) is the author/funder, who has granted bioRxiv a license to display the preprint in perpetuity. It is made available under aCC-BY 4.0 International license.

\section{Additional information:}

836 Correspondence and requests for materials should be addressed to Michael

837 D. Milsom. 


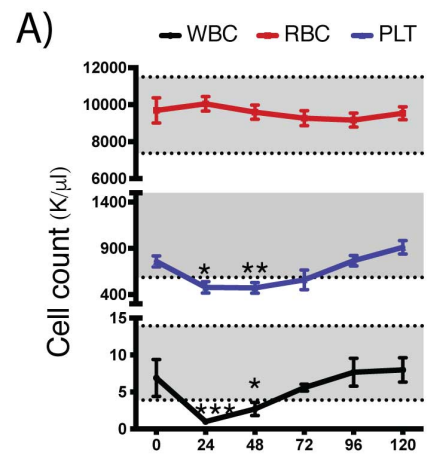

B)

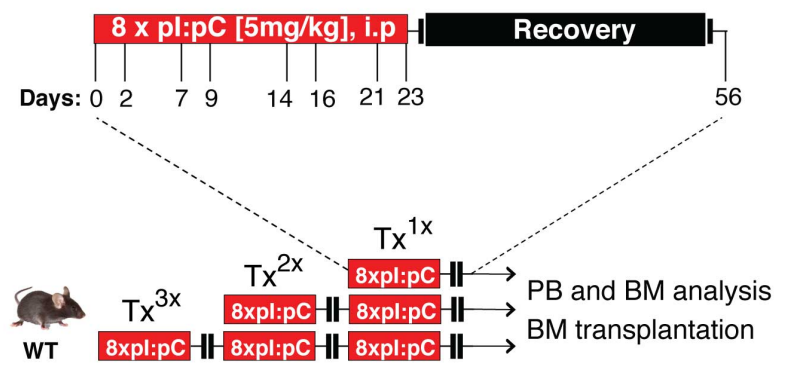

Time after pl:pC injection (hours)

C)

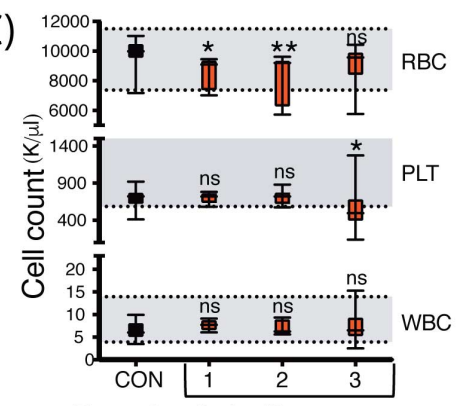

F)

Rounds of pl:pC treatment

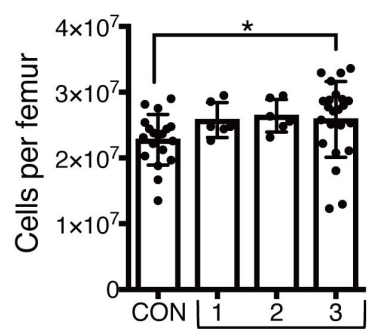

Rounds of pl:pC treatment

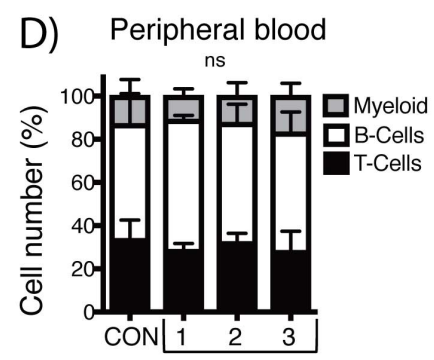

Rounds of pl:pC treatment
E) Bone marrow

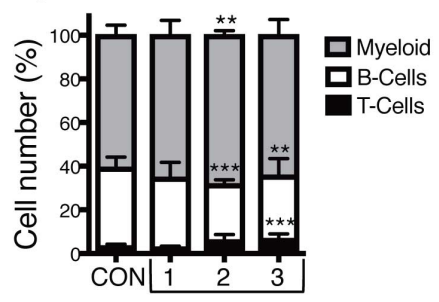

Rounds of pl:pC treatment

G)

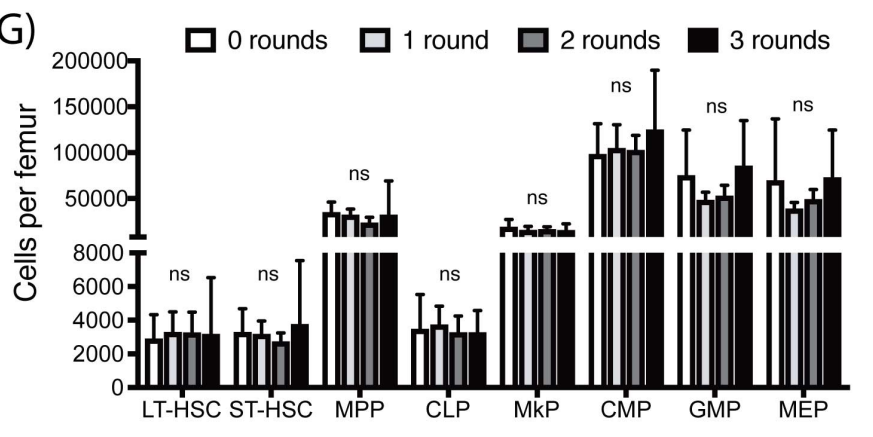

H)

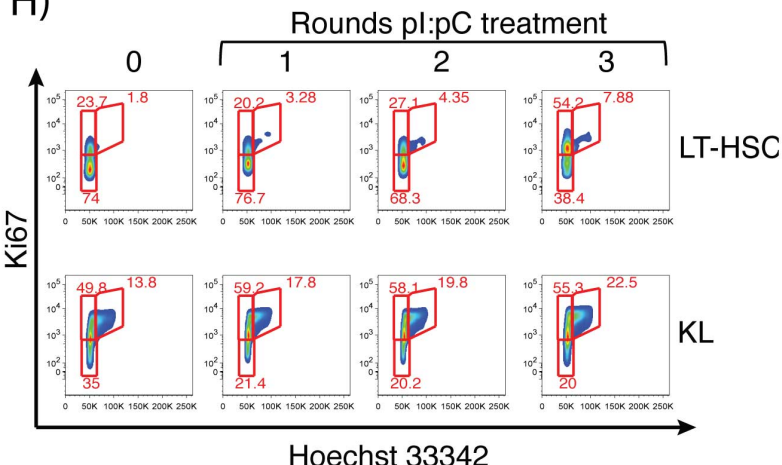

l)

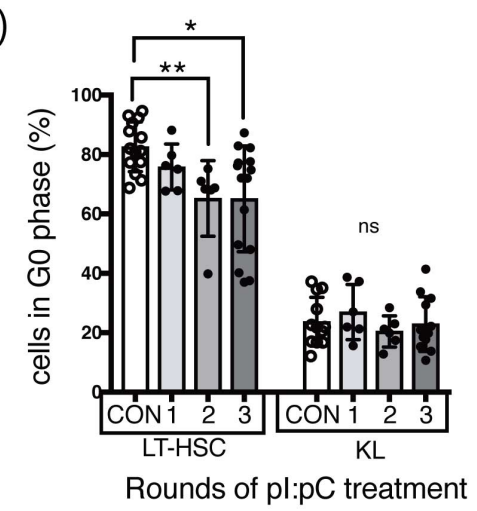

839 Figure S1. Repeated pl:pC treatment has a negligible sustained impact 
842 (A) Time course analysis of peripheral blood (PB) cell counts following a 843 single injection of C57BL/6J mice with pl:pC. The normal range values for 844 white blood cell (WBC), red blood cell (RBC) and platelet (PLT) counts are 845 indicated in grey. The mean \pm SD are indicated. $n=6-9$ mice per time point.

846 (B) Schematic representation of pl:pC dose escalation regimen. Each round 847 of treatment $\left(\mathrm{TX}^{1 \mathrm{X}}\right)$ consists of 8 i.p. injections with $\mathrm{pl}: \mathrm{pC}$ on the indicated 848 days, followed by a 33 day recovery period prior to the next round of 849 treatment. (C) PB cell counts of PBS-treated control mice (CON) and mice 850 treated with 1, 2 or 3 rounds with $\mathrm{pl}: \mathrm{pC}$, as indicated in Figure S1B. PB counts 851 were evaluated 5 weeks after the last pl:pC injection, $n=5-29$ per group. Box 852 and whiskers plots indicate median, interquartile range and minimum to 853 maximum values. (D-E) The relative frequency of myeloid $\left(C D 11 b^{+} / G R-1^{+}\right)$, B$854\left(\mathrm{~B} 220^{+}\right)$and T-cells $\left(\mathrm{CD} 4^{+} / \mathrm{CD}^{+}\right)$was measured by flow cytometry in PB (D) 855 and $\mathrm{BM}(\mathrm{E})$ of $\mathrm{CON}$ and $\mathrm{pl}: \mathrm{pC}$ treated mice, $\mathrm{n}=6-18$ per group. Mean $\pm \mathrm{SD}$ are 856 shown. (F) BM femur cellularity was enumerated 5 weeks after the indicated 857 treatment regimen. Mean \pm SD are shown. $n=6-23$ mice. (G) The relative 858 frequency of defined BM HSC and progenitor populations, as specified in 859 table S2, was determined by flow cytometry. Absolute frequencies were 860 calculated by adjusting for femur cellularity for each individual mouse. $n=6-12$ 861 per group. Mean \pm SD are shown. (H) Representative flow cytometry plots 862 showing determination of cell cycle status of LT-HSC and KL progenitor cells 863 using Hoechst and Ki67 staining. The gating strategy used to segregate cells 864 in the G0 (Ki67 and Hoechst low); G1 (Ki67 high, Hoechst low) and S/G2/M 865 (Ki67 and Hoechst high) phases of the cell cycle are shown, as are the 866 percentage of LT-HSCs or KL cells within each of these gates. (I) Relative 
867 frequency of quiescent (G0) LT-HSC and KL cells at 5 weeks after the

868 indicated treatment regimen. Mean \pm SD are shown. $\mathrm{n}=6-15$ mice. Statistical

869 significance between control and treatment groups was evaluated by one-way

870 ANOVA on ranks with Dunn's multiple comparison tests $\left({ }^{*} \mathrm{P}<0.05,{ }^{* *} \mathrm{P}<0.01\right.$, $\left.871 \quad{ }^{* * *} \mathrm{P}<0.001\right)$ 
A)

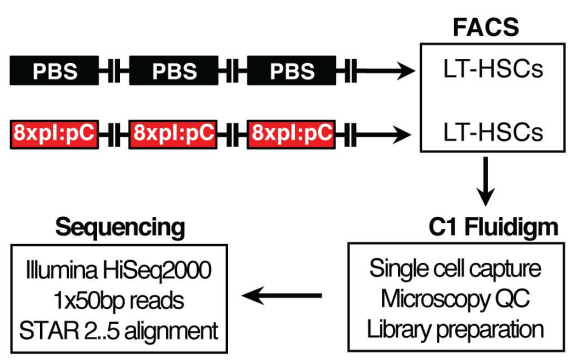

C)

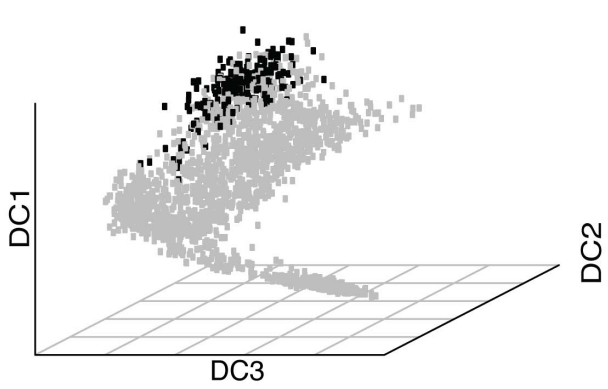

E)

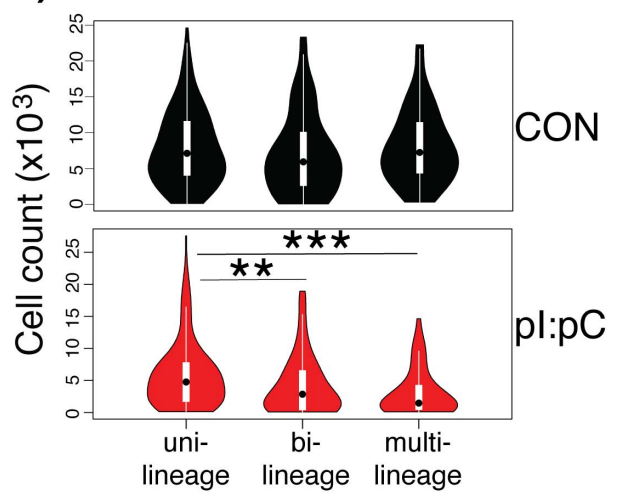

LT-HSC differentiation potential
B)

LT-HSC

(Lin- c-Kit+ Sca1+ CD34- Flk2-CD150+)

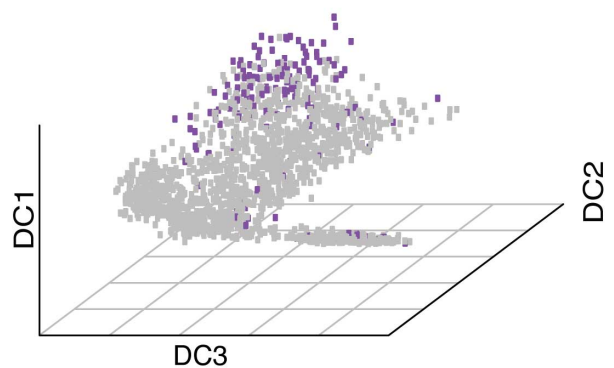

D)

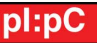

F)

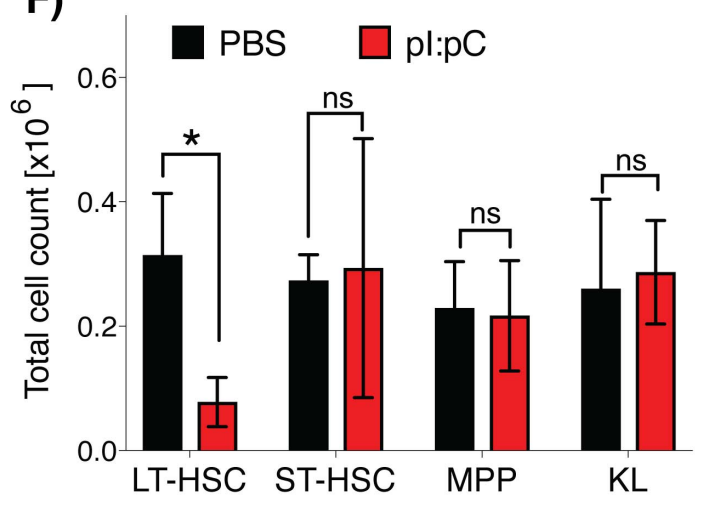

Figure S2. Immunophenotypic LT-HSCs from pl:pC treated mice retain a

874 similar transcriptional identity to LT-HSCs from CON mice, but show

875 functional impairment in in-vitro assays

876 (A) Schematic representation of the scRNAseq workflow. LT-HSC from CON

877 or $\mathrm{TX}^{3 \mathrm{X}}$ mice were isolated by flow cytometry at 5 weeks post-treatment, and

878 were subsequently subjected to scRNAseq using the C1 Fluidigm platform.

879 Downstream bioinformatics analysis was performed as described in the 
880 materials and methods section. (B-D) scRNAseq data was comparatively 881 analyzed relative to a publicly available set of scRNAseq data encompassing 882 murine bone marrow HSC and progenitor cells (Nestorowa et al., 2016). A 883 multi-dimensional diffusion map is presented with the entire HSC and 884 progenitor compartment indicated by grey dots. (B) The location of immuno885 phenotypically defined LT-HSCs, as previously defined in (Nestorowa et al., 886 2016), is indicated by purple dots in the diffusion plot. (C-D) The intersecting 887 variable genes between the previously published data set and the current 888 scRNAseq data were used to project LT-HSC from the current study onto the 889 pre-existing data set. LT-HSC isolated from (C) CON or (D) $\mathrm{TX}^{3 \mathrm{X}}$ mice are 890 indicated with black or red dots, respectively. These two populations 891 predominantly retain the same transcriptional signatures, suggesting that the 892 cell surface marker combinations used to identify and purify LT-HSCs, 893 essentially mark the same cell population regardless of treatment regimen. (E) 894 Violin plots representing the number of daughter cells per LT-HSC, 895 segregated by colony type from the in vitro single cell liquid culture assay using purified LT-HSCs described in Figure 1A (CON n=281 and pl:pC n=272 897 clones; $\mathrm{n}=3$ mice per group; white rectangle=interquartile range, black 898 dot=median). (F) LT-HSC (200 cells); ST-HSC (200 cells); MPP (1000 cells); 899 or KL (2000 cells) were purified from CON or $\mathrm{TX}^{3 \mathrm{X}}$ mice and directly placed 900 into liquid culture. The total number of progeny was enumerated on day 10 of 901 culture, demonstrating that the proliferative potential of LT-HSCs was 902 compromised, while that of ST-HSCs and progenitors was not. Statistical 903 analysis was performed using an unpaired two-tailed Student's t-test, $n=3-5$ 904 mice, data represent mean \pm SD. Unless otherwise stated, statistical 
bioRxiv preprint doi: https://doi.org/10.1101/2020.08.01.230433; this version posted August 3, 2020. The copyright holder for this preprint (which was not certified by peer review) is the author/funder, who has granted bioRxiv a license to display the preprint in perpetuity. It is made available under aCC-BY 4.0 International license.

905 significance between control and treatment groups was evaluated by one-way

906 ANOVA on ranks with Dunn's multiple comparison tests (ns=P $>0.05,{ }^{*} \mathrm{P}<0.05$,

907 $\left.{ }^{* *} \mathrm{P}<0.01,{ }^{* * *} \mathrm{P}<0.001\right)$. 
A)

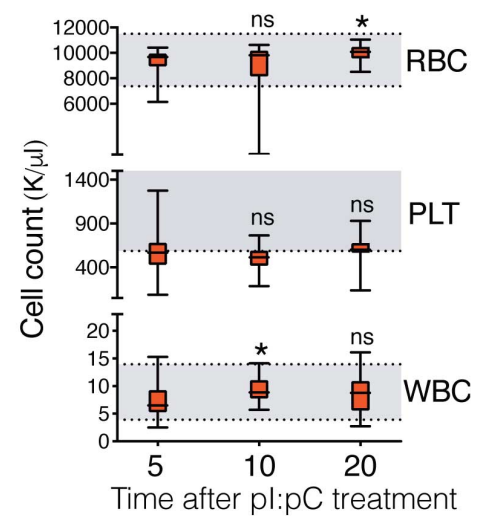

C) (weeks)

Bone marrow

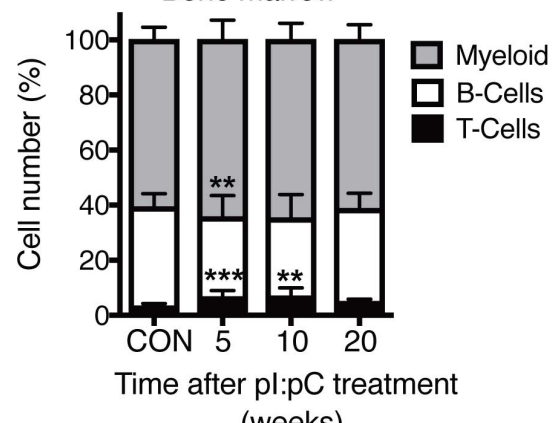

E)

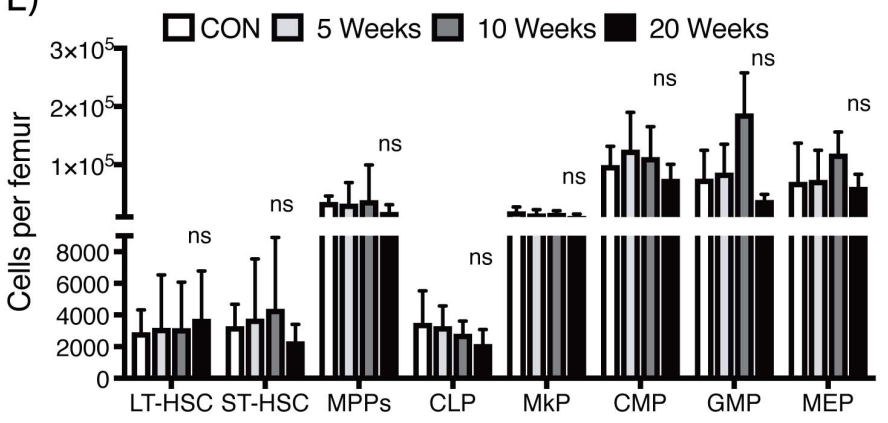

G)

\begin{tabular}{|c|r|r|r|}
\hline \multicolumn{4}{|c|}{ Confidence intervals for } \\
\hline \multicolumn{4}{|c|}{ 1/(stem cell frequency) } \\
\hline Group & \multicolumn{1}{|c|}{ Lower } & \multicolumn{1}{|c|}{ Estimate } & \multicolumn{1}{c|}{ Upper } \\
\hline PBS & 78678 & 54042 & 37120 \\
\hline 5wk plpC & 1191538 & 791051 & 525172 \\
\hline 10wk plpC & 1651149 & 1078255 & 704137 \\
\hline 20wk plpC & 1712237 & 1116341 & 727829 \\
\hline
\end{tabular}

908

H)

\section{WT mice.}

B)

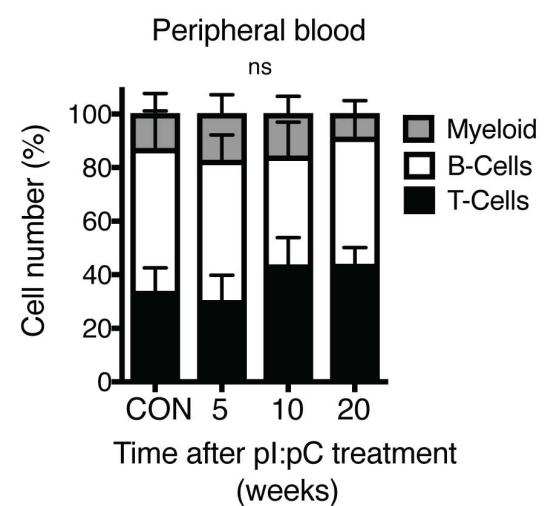

D)

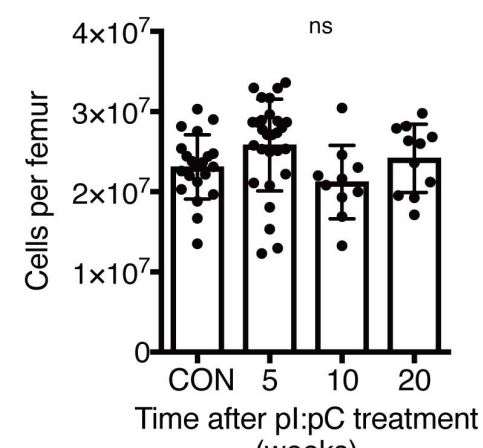
(weeks)

F)

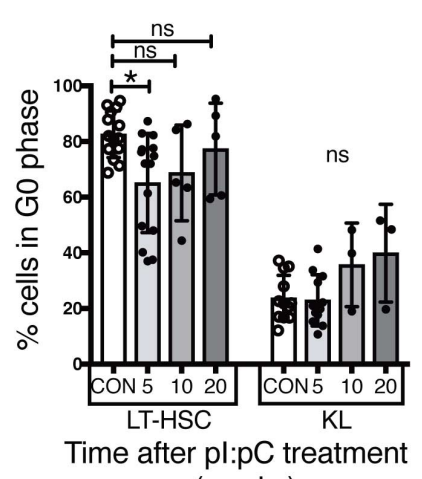
(weeks)

Pairwise tests for differences in stem cell frequencies
\begin{tabular}{|l|c|r|r|r|}
\hline Group 1 & Group 2 & \multicolumn{1}{c|}{ Chisq } & DF & Pr(>Chisq) \\
\hline PBS & 5wk plpC & 92.2 & 1 & $7.85 \mathrm{E}-22$ \\
\hline PBS & 10wk plpC & 109 & 1 & $1.80 \mathrm{E}-25$ \\
\hline PBS & 20wk plpC & 119 & 1 & $1.34 \mathrm{E}-27$ \\
\hline 5wk plpC & 10wk plpC & 1.04 & 1 & 0.309 \\
\hline 5wk plpC & 20wk plpC & 1.38 & 1 & 0.24 \\
\hline 5wk plpC & 20wk plpC & 1.38 & 1 & 0.24 \\
\hline 10wk plpC & 20wk plpC & 0.0129 & 1 & 0.91 \\
\hline
\end{tabular}

Figure S3. Characterization of hematological parameters and limiting dilution transplantation analysis after 5,10 or 20 weeks recovery in $\mathrm{TX}^{3 \mathrm{X}}$

(A) The PB counts of $\mathrm{TX}^{3 \mathrm{X}}$ mice was measured at 5, 10 or 20 weeks after the last pl:pC injection, Box and whiskers plots indicate median, interquartile 
914 range and minimum to maximum values, $n=17-44$. (B-C) The relative

915 frequency of myeloid $\left(\mathrm{CD} 11 \mathrm{~b}^{+} / \mathrm{Gr}-1^{+}\right)$, B- $\left(\mathrm{B} 220^{+}\right)$and T-cells $\left(\mathrm{CD} 4^{+} / \mathrm{CD} 8^{+}\right)$

916 was measured by flow cytometry in both the (B) PB and (C) BM of CON and

$917 \mathrm{TX}^{3 \mathrm{X}}$ treated mice, at the indicated time points after treatment. Mean \pm SD are

918 shown. $n=6-18$. (D) The BM cellularity within the femora of CON and TX ${ }^{3 X}$

919 mice was evaluated in mice that were sacrificed at the indicated time point

920 after treatment. Mean \pm SD are shown. $n=10-28$ mice. (E) The absolute

921 number of cells within defined immunophenotypic compartments (see Table

922 S2) within the $\mathrm{BM}$ of $\mathrm{CON}$ and $\mathrm{TX}^{3 \mathrm{X}}$ mice at the indicated time point post-

923 treatment was assessed by flow cytometry. This was followed by adjustment

924 to take account of BM cellularity for each individual mouse, $n=6-12$. (F) The

925 percentage of quiescent (G0) LT-HSC and KL cells within the BM of CON and

$926 \mathrm{TX}^{3 \mathrm{X}}$ mice, harvested at the indicated time point after treatment, is shown.

927 Mean \pm SD, $n=3-15$ mice. Statistical significance between control and

928 treatment groups was evaluated by one-way ANOVA on ranks with Dunn's

929 multiple comparison tests (ns=P>0.05, ${ }^{*} \mathrm{P}<0.05,{ }^{* *} \mathrm{P}<0.01,{ }^{* * *} \mathrm{P}<0.001$ ). (G-H)

930 The statistical analysis of the limiting dilution experiment shown in Figure 2D

931 is shown in these tables. (G) The estimate of HSC frequency in BM for each

932 experimental group is shown, as are the $95 \%$ confidence intervals for this

933 estimate. (H) Pairwise analysis of experimental groups using Chi-squared

934 test. 
A)

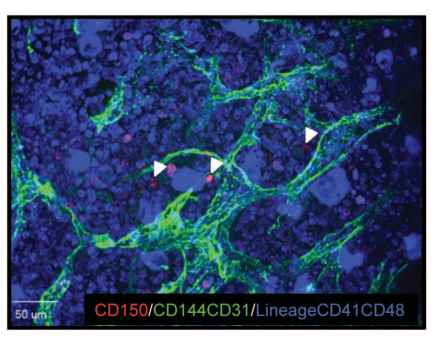

C)

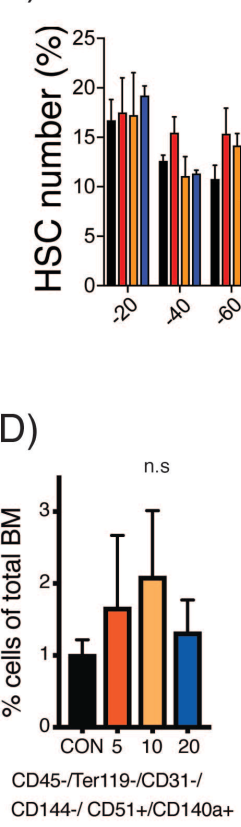

B)

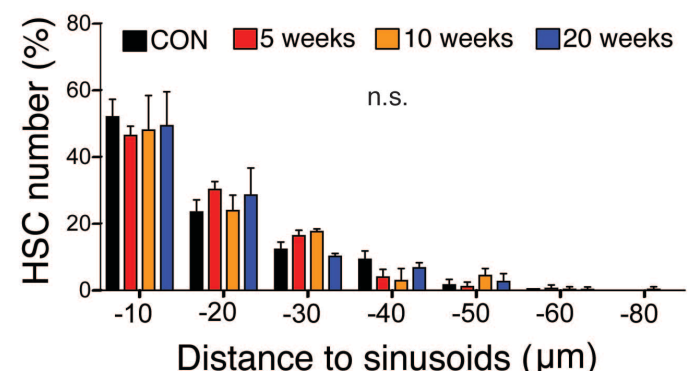

aCON $\square 5$ weeks $\square 10$ weeks $\square 20$ weeks

${ }^{*} \mathrm{p}=0.02 \quad \mathrm{p}=0.91 \quad \mathrm{p}=0.80$
E)

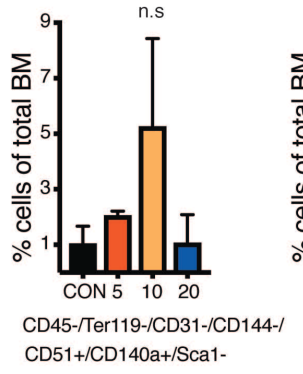

F)

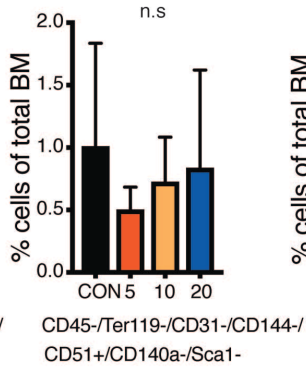

G)

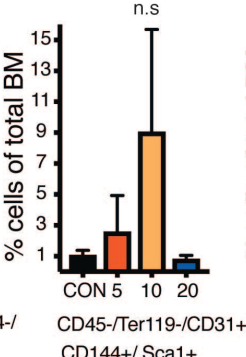

H)

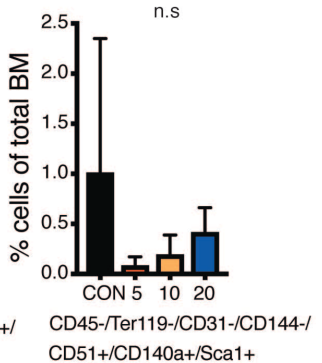

936 Figure S4. Repetitive exposure to inflammatory stress has a limited

937 impact on BM niche architecture and composition.

938 (A) Representative immuno-fluorescence image of a whole mount cross

939 section of the sternum, used for the quantification of the spatial distribution of

940 HSCs relative to the BM vasculature (sinusoids or arterioles). HSCs were

941 identified by staining for CD150 expression (in red) and negativity for CD41

942 and CD48 lineage markers (in blue). HSCs are indicated by white

943 arrowheads. Endothelial cells were defined by positivity for CD144 and CD31

944 expression (in green). (B-C) The spatial relationship between HSCs and the

945 BM vasculature was quantified by measuring the shortest distance between 
946 HSCs and (B) sinusoids or (C) arterioles, $n=4-5$ mice, $n=157-492$ HSCs. Two-

947 sample Kolmogorov-Smirnov tests were used for the comparison of

948 distribution patterns between CON mice and the different recovery time

949 points. (D-H) Analysis of the relative composition of defined niche

950 components within the BM was performed using flow cytometry after staining

951 with antibodies directed against a combination of CD45, Ter119, CD51,

952 CD31, CD144, CD140a, Sca-1. Based on previous literature, these

953 populations were analogous to (D) Nestin ${ }^{+}$like stromal cells; (E) Cxcl12

954 abundant reticular; (F) osteoblast; (G) endothelial; and (H) mesenchymal stem

955 cells. Mean \pm SD are shown, $n=3-9$ mice. Statistical significance between

956 control and treatment groups was evaluated by one-way ANOVA on ranks

957 with Dunn's multiple comparison tests (n.s=p>0.05). 

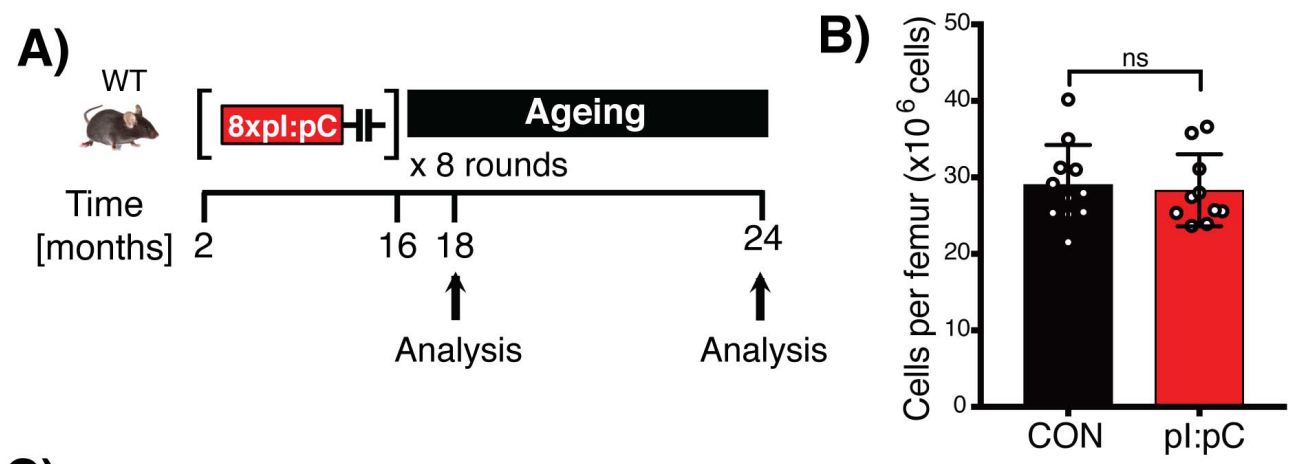

C)

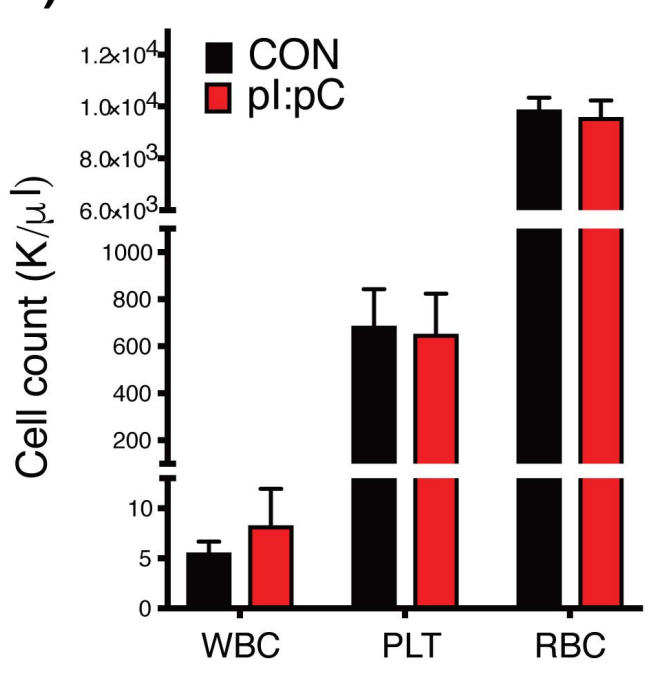

D)
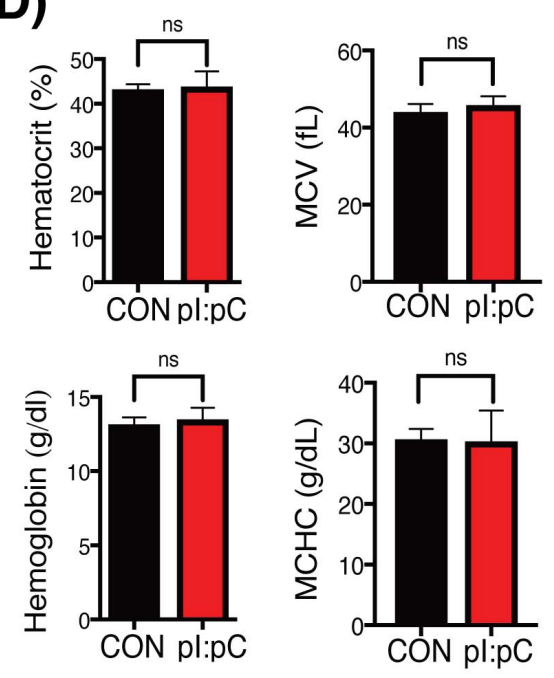

E)

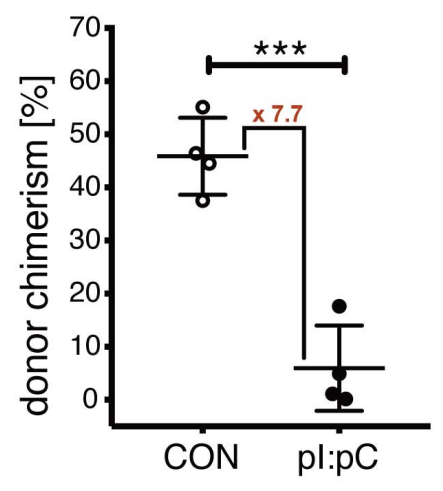

F)

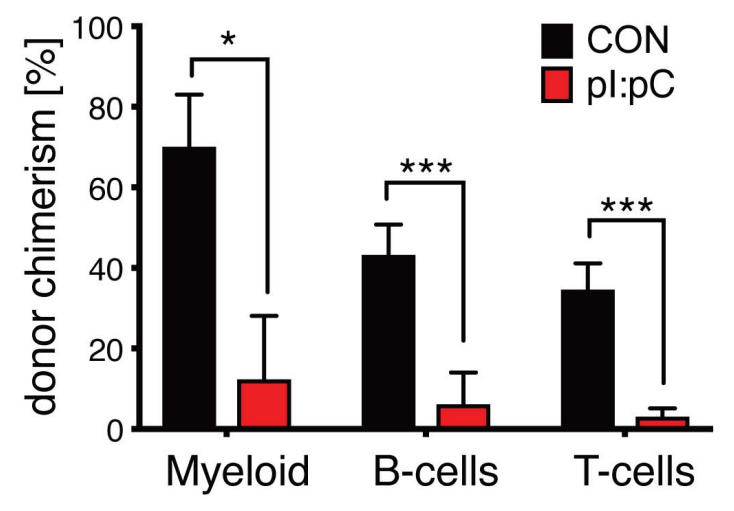

Figure S5. PB counts and BM cellularity at 18 months of age are not

961 affected in mice exposed to repetitive to inflammatory stress, but HSCs

962 demonstrate a profound functional engraftment defect at $\mathbf{2 4}$ months of 963 age.

964 (A) Schematic representation of the treatment schedule. C57BL/6J mice were 965 treated for 8 consecutive rounds with pl:pC (64 injections). Controls (CON) 
966 represent either age matched non-treated mice, or age-matched mice that

967 were subject to PBS injections in place of pl:pC. At the time of the last

968 injection, the mice were 16 months old (68wk). They were then either

969 sacrificed at 18 months of age and analyzed, or were left to age for an

970 additional 8 months until they reached 24 months of age. (B-D) PB and BM

971 parameters evaluated at 18 months of age. (B) BM cellularity (C) Numbers of

972 leukocytes (WBC), platelets (PLT) and red blood cells (RBC) found in the PB.

973 (D) Erythrocyte related parameters, including mean cell volume (MCV) and

974 mean cell hemoglobin content $(\mathrm{MCHC})$. Mean $\pm \mathrm{SD}$ are shown, $\mathrm{n}=10-12$ mice

975 per group. (E-F) BM isolated from mice at 24 months of age was assessed for

976 functional activity using a competitive repopulation assay, where test BM cells

977 from individual donors were co-injected into recipients along with a 1:1 ratio of

978 competitor BM cells. (E) Analysis of the contribution of test BM cells to donor

979 PB leukocyte chimerism at 6 months post-transplantation demonstrates a 7.7-

980 fold reduction in competitive repopulation activity in BM cells from pl:pC

981 treated mice. (F) Analysis of the relative contribution of test BM to the myeloid

$982\left(\mathrm{CD} 11 \mathrm{~b}^{+} \mathrm{Gr}-1^{+}\right), \mathrm{B}-\mathrm{cell}\left(\mathrm{B} 220^{+}\right)$and $\mathrm{T}$-cell $\left(\mathrm{CD} 4^{+} / \mathrm{CD} 8^{+}\right)$lineages at 6 months

983 post-transplantation. mean \pm SD are shown, $n=3-4$ mice per group. Statistical

984 significance was determined by unpaired two-tailed t-test $\left({ }^{*} \mathrm{P}<0.05\right.$, $985 \quad * * * P<0.001)$. 
bioRxiv preprint doi: https://doi.org/10.1101/2020.08.01.230433; this version posted August 3, 2020. The copyright holder for this preprint (which was not certified by peer review) is the author/funder, who has granted bioRxiv a license to display the preprint in perpetuity. It is made available under aCC-BY 4.0 International license.

986

987

\begin{tabular}{|c|c|c|c|c|c|c|c|c|c|}
\hline & Clone & $\begin{array}{l}\text { LT-, ST- } \\
\text { HSCs, } \\
\text { MPPs }\end{array}$ & $\begin{array}{l}\text { LT-HSCs } \\
\text { plus Ki67 }\end{array}$ & $\begin{array}{l}\text { LT-HSCs } \\
\text { plus GFP }\end{array}$ & LSKs & $\begin{array}{l}\text { Committed } \\
\text { Progenitors }\end{array}$ & $\begin{array}{l}\text { Mature Blood and } \\
\text { Bone Marrow } \\
\text { Cells }\end{array}$ & \begin{tabular}{|l} 
Bone Marrow \\
Cells
\end{tabular} & \begin{tabular}{|l} 
Single LT-HSC \\
colony \\
differentiation
\end{tabular} \\
\hline c-kit (CD117) & 2B8 & APC & APC & APC & APC & APC & & APC & \\
\hline Sca1 & D7 & APC-Сy7 & APC-Сy7 & APC-Cy7 & FITC & APC-Су7 & & FITC & \\
\hline CD150 & TC15-12F12.2 & Pe-Cy5 & PE-Cy5 & PE-Cy5 & & & & PE-Cy5 & \\
\hline CD48 & HM48-1 & PacBlue & & PE & & & & PacBlue & \\
\hline CD34 & RAM34 & FITC & AF700 & PacBlue & & FITC & & & \\
\hline CD41 & MWReg30 & PE & & & & & & & PacBlue \\
\hline \begin{tabular}{|l} 
Ki67 \\
Hoechst
\end{tabular} & B56 & & $\begin{array}{l}\text { FITC } \\
\text { H3570 }\end{array}$ & & & & & & \\
\hline CD5 & $53-7.3$ & Biotin & Pe-Cy7 & Biotin & Biotin & Pe-Сy7 & & Pe-Cy7 & \\
\hline CD8a & 53-6.7 & Biotin & Pe-Cy7 & Biotin & Biotin & Pe-Cy7 & PE & Pe-Cy7 & \\
\hline CD11b & $\mathrm{M} 1 / 70$ & Biotin & Pe-Cy7 & Biotin & Biotin & Рe-Сy7 & APC & Pe-Cy7 & APC-Сy7 \\
\hline B220 & RA3-6B2 & Biotin & Pe-Cy7 & Biotin & Biotin & Pe-Cy7 & PE, APC & Pe-Cy7 & \\
\hline Gr1 & RB6-8C5 & Biotin & Pe-Cy7 & Biotin & Biotin & Рe-Сy7 & & Рe-Сy7 & APC-Cy7 \\
\hline Ter119 & TER-119 & Biotin & Pe-Cy7 & Biotin & Biotin & Pe-Cy7 & & Pe-Cy7 & FITC \\
\hline Streptavidin & S3E11 & Pe-Cy7 & & Pe-Cy7 & $\mathrm{PE}$ & & & & \\
\hline $\begin{array}{l}\text { CD16/32 } \\
\text { CD127 }\end{array}$ & $\begin{array}{c}93 \\
\text { A7R34 }\end{array}$ & & & & & $\begin{array}{l}\text { eFluor450 } \\
\text { PE }\end{array}$ & & & \\
\hline CD4 & GK1.5 & & & & & & $\mathrm{PE}$ & & \\
\hline CD71 & R17217 & & & & & & & & PE \\
\hline CD42d & $1 \mathrm{C} 2$ & & & & & & & & APC \\
\hline CD45.1 & A20 & & & & & & PacBlue & eFluor780 & \\
\hline CD45.2 & 104 & & & & & & FITC & AF700 & \\
\hline
\end{tabular}

988

eBioscience BD Bioscience Biolegend Invitrogen 
bioRxiv preprint doi: https://doi.org/10.1101/2020.08.01.230433; this version posted August 3, 2020. The copyright holder for this preprint (which was not certified by peer review) is the author/funder, who has granted bioRxiv a license to display the preprint in perpetuity. It is made available under aCC-BY 4.0 International license.

990 Table S2. Definition of specific immunophenotypically-defined cell populations 991 that have been analyzed in the manuscript.

\begin{tabular}{|c|l|l|}
\hline Abbreviation & \multicolumn{1}{|c|}{ Population } & \multicolumn{1}{c|}{ Surface markers } \\
\hline LT-HSC & long term hematopoietic stem cell & Lin (-) c-kit(+) sca-1(+) CD150(+) CD48(-) CD34(-) \\
\hline ST-HSC & short term hematopoietic stem cell & Lin (-) c-kit(+) sca-1(+) CD150(+) CD48(-) CD34(+) \\
\hline HSC & hematopoietic stem cell & Lin (-) c-kit(+) sca-1(+) CD150(+) CD48(-) \\
\hline MPP & multi potent progenitor & Lin (-) c-kit(+) sca-1(+) CD150(+) CD48(+) \\
\hline CLP & common lymphoid progenitor & Lin(-)CD127(+);sca-1(mid) C-kit(mid) \\
\hline MRP & megakaryocytic progenitor & Lin (-) c-kit(+) sca-1(-) CD150(+) CD41(+) \\
\hline CMP & common myeloid progenitor & Lin (-) c-kit(+) sca-1(-) CD16/32(mid) CD34(+) \\
\hline GMP & granulocytic-monocytic progenitor & Lin (-) c-kit(+) sca-1(-) CD16/32(hi) CD34(+) \\
\hline MEP & megakaryocytic-erythroid progenitor & Lin (-) c-kit(+) sca-1(-) CD16/32(low) CD34(-) \\
\hline KL & oligopotent progenitors & Lin (-) c-kit(+) sca-1(-) \\
\hline Lin- & lineage negative cells & CD4(-) CD8(-) B220(-) Ter-119(-) CD11b(-) Gr-1(-) \\
\hline Lin+ & lineage positive cells & CD4(+) CD8(+) B220(+) Ter-119(+) CD11b(+) Gr-1(+) \\
\hline T-cell & mature T-cells & CD4(+) and/or CD8(+) \\
\hline B-cell & mature B-cells & B220(+) \\
\hline Myeloid & mature myeloid cells & CD11b(+) Gr-1(+) \\
\hline CAR & Cxcl12 abundant reticular cell & CD45/Ter119(-) CD51(+) CD31(-) CD144(-) CD140alpha(+) sca-1(-) \\
\hline OB & osteoblast & CD45/Ter119(-) CD144(-) CD51(+) CD31(-) CD140alpha(-) sca-1(-) \\
\hline EC & endothelial cell & CD45/Ter119(-) CD31(+) CD144(+) sca-1(+) \\
\hline MSC & mesenchimal stem cell & CD45/Ter119(-) CD51(+) CD31(-) CD140alpha(+) sca-1(+) \\
\hline Nestin (+) like SC & Nestin(+) like stromal cells & CD45/Ter119(-) CD144(-) CD51(+) CD31(-) CD140alpha(+) \\
\hline
\end{tabular}

992 